\title{
An Analytical Method for Determining the Load Distribution of Single-Column Multibolt Connection
}

\author{
Nirut Konkong and Kitjapat Phuvoravan \\ Department of Civil Engineering, Faculty of Engineering, Kasetsart University, Bangkok 10900, Thailand \\ Correspondence should be addressed to Kitjapat Phuvoravan; fengkpp@ku.ac.th
}

Received 23 March 2017; Accepted 28 May 2017; Published 6 July 2017

Academic Editor: Dimitris Rizos

Copyright (c) 2017 Nirut Konkong and Kitjapat Phuvoravan. This is an open access article distributed under the Creative Commons Attribution License, which permits unrestricted use, distribution, and reproduction in any medium, provided the original work is properly cited.

\begin{abstract}
The purpose of this research was to investigate the effect of geometric variables on the bolt load distributions of a cold-formed steel bolt connection. The study was conducted using an experimental test, finite element analysis, and an analytical method. The experimental study was performed using single-lap shear testing of a concentrically loaded bolt connection fabricated from G550 cold-formed steel. Finite element analysis with shell elements was used to model the cold-formed steel plate while solid elements were used to model the bolt fastener for the purpose of studying the structural behavior of the bolt connections. Material nonlinearities, contact problems, and a geometric nonlinearity procedure were used to predict the failure behavior of the bolt connections. The analytical method was generated using the spring model. The bolt-plate interaction stiffness was newly proposed which was verified by the experiment and finite element model. It was applied to examine the effect of geometric variables on the single-column multibolt connection. The effects were studied of varying bolt diameter, plate thickness, and the plate thickness ratio $\left(t_{2} / t_{1}\right)$ on the bolt load distribution. The results of the parametric study showed that the $t_{2} / t_{1}$ ratio controlled the efficiency of the bolt load distribution more than the other parameters studied.
\end{abstract}

\section{Introduction}

A bolt connection is generally used in cold-formed steel structures. It can result in a high-stress concentration at contact regions, especially with thin cold-formed steel members. The shearing of cold-formed steel, bearing on material in front of the bolt, tearing of the cold-formed steel in the net section, and shearing of the bolt are the main failure modes of a single bolt connection. In multibolt connections, the failure modes are identified by numerical and analytical methods, with the results showing combined bearing failure and net-section failure modes $[1,2]$. The failure behavior of a multibolt connection is considered in two steps as (a) the load distribution between bolts, which is the process for considering the stress bypass in the multibolt connection, and (b) local stresses analysis as the bearing stress and net-section stress around a critical hole, which is used to investigate ensuring a safety margin of connection [3-5]. Practically, the lap shear connection is used for tension in a structural member such as the diagonal and tension chord truss element. It is designed using a multiple bolt connection with even bolt load distribution. The bolts in a row in the loading direction are assumed to have an equal distribution of load among the bolts. In an actual lap connection, the behavior of each bolt in a row is different due to an unequal load distribution that also results from the stiffness of the single bolt deformation and plate deformation between bolts as shown in Figure 1, where the evolution of the internal forces versus the applied force $(P)$ is demonstrated with a five-bolt connection in which $\delta$ and $\delta_{b-i}$ are the connection elongation and bolt deformation.

In the first step, the connection evolves elastic behavior with the outer bolts being more loaded than the inner ones. In the second step, the outer bolt rows reach their elastic limit strength but the inner bolt rows are still in the elastic stage. In the third step, the plastic behavior is distributed to the inner bolt rows. In the fourth step, the plastic behavior is developed in all the bolt rows. However, the limitation of the coldformed ductility between the bolt-plate in bearing may be reached before the connection develops full plastic strength. 


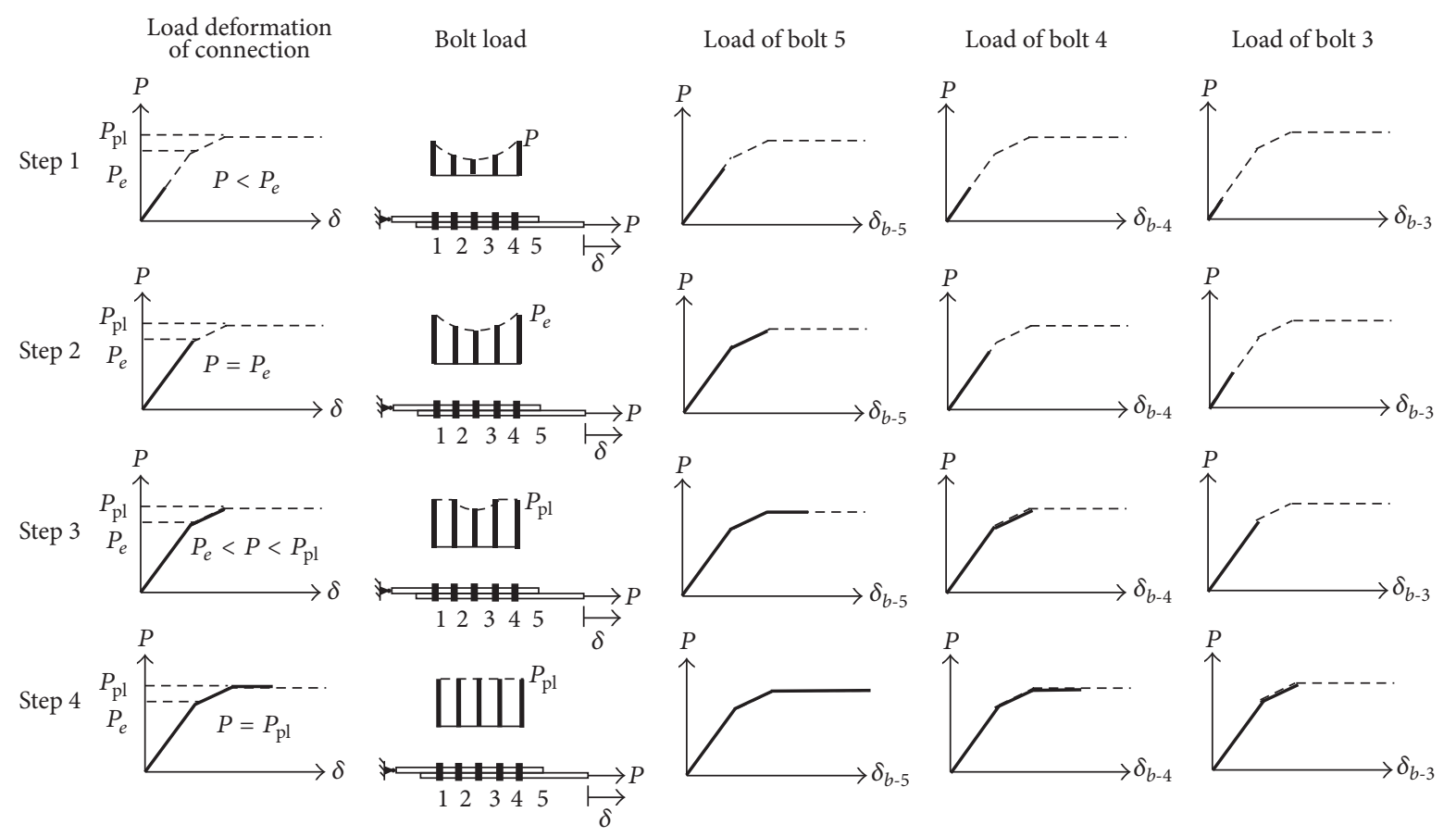

FIgURE 1: Stages of force distribution in bolt connections [6].

These failures result in a lower average bearing stress value per bolt hole of the multibolt connection. In this case, the connection would not develop the ultimate bearing capacity as recommended by the design method $[6,7]$. Bolt load prediction is a complex procedure involving the establishment of the bolt load distribution. The stiffness components (the axial stiffness of the plate and the interaction of the bolt-plate) must be included in the investigation of bolt load distribution. However, the interaction stiffness of the bolt-plate is not easily defined in a closed-form solution because the analysis requires knowledge of the influenced parameters such as the shear deformation of the bolt, bending deformation of the bolt, bearing deformation of the plate, bearing deformation of the bolt, and deformation of the plate between bolts. Thus, the equation of the bolt-plate interaction stiffness in industry today is derived by using a semiempirical approach based on the testing data [8-10]. The weakness of these empirical equations is that they ignore the shear deformation assumption in the bolt component which is dominated by the short bolt length.

This study describes the method of analysis for determining the load distribution among bolts in a single-column multibolt connection. A bolt-plate interaction stiffness equation is proposed which is verified by the experimental test and finite element analysis (FEA). The experimental investigation was performed using lap shear bolt connection testing and the connections were fabricated from cold-formed steel.

\section{Material Properties and Model Description}

The laboratory test was performed using G550 cold-formed steel with a plate thickness of $1.0 \mathrm{~mm}$ for the bolt connection test. G550 is a hot-dipped zinc-coated structural steel and has a minimum yield strength of $550 \mathrm{MPa}$. The material properties for G550 steels were specified by following ASTM Standards A370-07 [11] as shown in Table 1. Following the research objective and scope, the possibility of bolting shear failure was eliminated by using M5 Grade 8.8 steel bolts conforming to ASTM A325M [12] as shown in Table 2.

The bolt connection specimen and the hole size are shown in Figure 2. The bolts and nuts were assembled with integral washers that were tightened by hand, which allowed for slip in the connection after the initial loading.

The bolt connection specimens were tested using a universal testing machine (UTM) in the structural laboratory of Kasetsart University, Bangkok, Thailand, as shown in Figure 3(a). A typical bolted shear connection test setup is shown in Figure 3(b). The load and the axial deformation were measured to describe the connection failure behavior. The load was applied to the specimen using displacement control with a speed of $1 \mathrm{~mm} /$ minute. A linear variable differential transformer (LVDT) was installed to measure the elongation of a single bolt connection over a distance of $200 \mathrm{~mm}$ from the center line. The load was gradually applied until either the specimen failed or the specimen entered into plastic deformation. Once the applied load began to drop, even though the specimen continued to elongate, the test was stopped.

\section{Finite Element Model and Validation}

In the present study, the ANSYS finite element package [13] was used to predict the failure behavior of the bolt connection as shown in Figure 4. Nonlinear finite element analysis was used to compare and validate the results of the single bolt connection test. The nonlinear geometry, material 


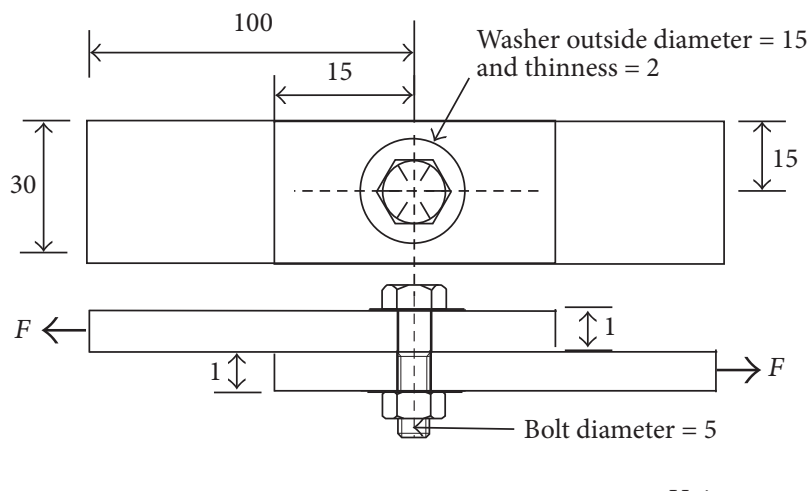

(a) Bolt connection geometries

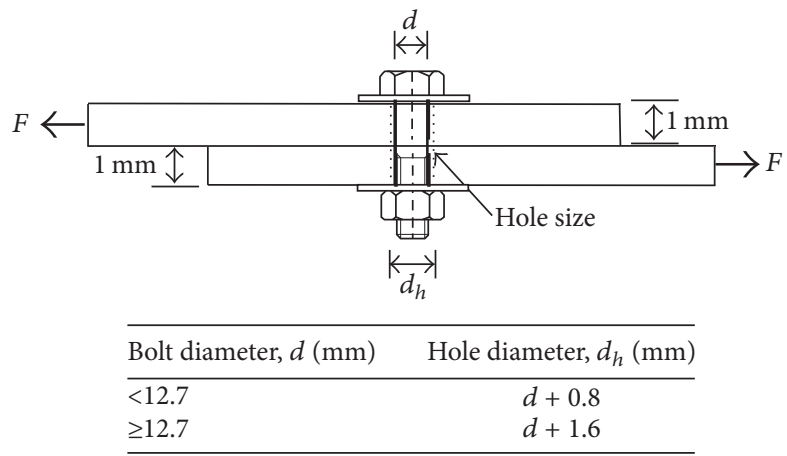

(b) Hole size

FIGURE 2: Bolt connection specimens.

TABLE 1: Material properties of cold-formed steel, G550-1T.

\begin{tabular}{lcccccccr}
\hline & \multicolumn{4}{c}{ Test number } & \multicolumn{2}{c}{ COV } \\
& CT-1 & CT-2 & CT-3 & CT-4 & CT-5 & Mean & SD \\
\hline$T(\mathrm{~mm})$ & 1.045 & 1.045 & 1.044 & 1.045 & 1.045 & 1.04 & 0.0004 & 0.04 \\
$W(\mathrm{~mm})$ & 12.64 & 12.65 & 12.59 & 12.58 & 12.52 & 12.59 & 0.0522 \\
$F_{y}(\mathrm{MPa})$ & 608.47 & 605.77 & 605.90 & 617.50 & 606.46 & 608.82 & 4.9715 & 0.41 \\
$F_{u}(\mathrm{MPa})$ & 627.00 & 622.50 & 625.50 & 630.00 & 620.00 & 625.00 & 3.8890 & 0.62 \\
$E(\mathrm{GPa})$ & 213.51 & 213.49 & 213.49 & 213.58 & 213.58 & 213.53 & 44.1757 & 0.02 \\
$F_{u} / F_{y}$ & 1.03 & 1.02 & 1.03 & 1.02 & 1.02 & 1.02 & 0.0054 & 0.53 \\
\hline
\end{tabular}

Remark. $F_{y}$ is the yield stress, $F_{u}$ is the ultimate stress, $E$ is the modulus of elasticity, $T$ is the plate thickness, $W$ is the width of coupon test specimen, COV is the coefficient of variation, and SD is the standard deviation.

TABLE 2: Material properties of bolts.

\begin{tabular}{|c|c|c|c|c|c|c|c|c|}
\hline & \multicolumn{6}{|c|}{ Test number } & \multirow{2}{*}{ SD } & \multirow{2}{*}{$\mathrm{COV}$} \\
\hline & BT-1 & BT-2 & BT-3 & BT-4 & BT-5 & Mean & & \\
\hline$d(\mathrm{~m})$ & 4.93 & 4.97 & 4.97 & 4.97 & 4.94 & 4.95 & 0.019 & 0.393 \\
\hline$F_{y}(\mathrm{MPa})$ & 930.00 & 949.00 & 927.00 & 976.00 & 872.00 & 930.80 & 38.232 & 4.107 \\
\hline$F_{u}(\mathrm{MPa})$ & 963 & 930 & 963 & 997 & 909 & 952.40 & 33.908 & 3.560 \\
\hline$E(\mathrm{GPa})$ & 204.08 & 204.08 & 204.09 & 204.10 & 204.09 & 204.08 & 7.385 & 0.003 \\
\hline
\end{tabular}

Remark. $d$ is the bolt diameter.

nonlinearity, and contact problem were modeled in the finite element model. The cold-formed steel was modeled using eight nodes with six degrees of freedom at each node shell elements (SHELL281) as shown in Figure 4(b).

Three-dimensional, 20-node solid elements (SOLID186) with three degrees of freedom at each node were used to model the steel bolts and the washers, as shown in Figure 4(c). Contact between the steel plates, steel bolts, washers, and wall of the holes was defined as the contact elements (CONTA173 and TARGE170). The pure penalty contact algorithm was used to solve the constrained optimization contact problem as shown in Figures 4(d)-4(e). The mesh size was controlled by the aspect ratios (length-to-width ratio) which were selected to be close to 1.0 for all components. Around the bolt holes, fine mesh was utilized in order to transfer the stress from the bolt to the cold-formed steel plate. The nodes along the end plates were restrained with geometric boundary conditions as pinned and roller support. The uniform load was applied along the end plate line $B$ with the displacement control as shown in Figure 4(f). The static friction between the steel plates was neglected due to the smooth coating surfaces. The actual stress-strain values from the cold-formed steel tensile testing were converted to the true stress $\left(\sigma_{\text {true }}\right)$ and strain $\left(\sigma_{\text {true }}\right)$ which imposed a multilinear isotropic hardening model as shown in Figure $4(\mathrm{~g})$. It was converted using

$$
\begin{aligned}
& \sigma_{\text {true }}=\sigma_{\text {test }}\left(1+\varepsilon_{\text {test }}\right), \\
& \varepsilon_{\text {true }}=\ln \left(1+\varepsilon_{\text {test }}\right) .
\end{aligned}
$$

The large deflection option was activated to achieve nonlinear geometry behavior. By turning on this option, iterative solving and updating of the stiffness matrix based on the incremental nodal displacements at each equilibrium iteration 


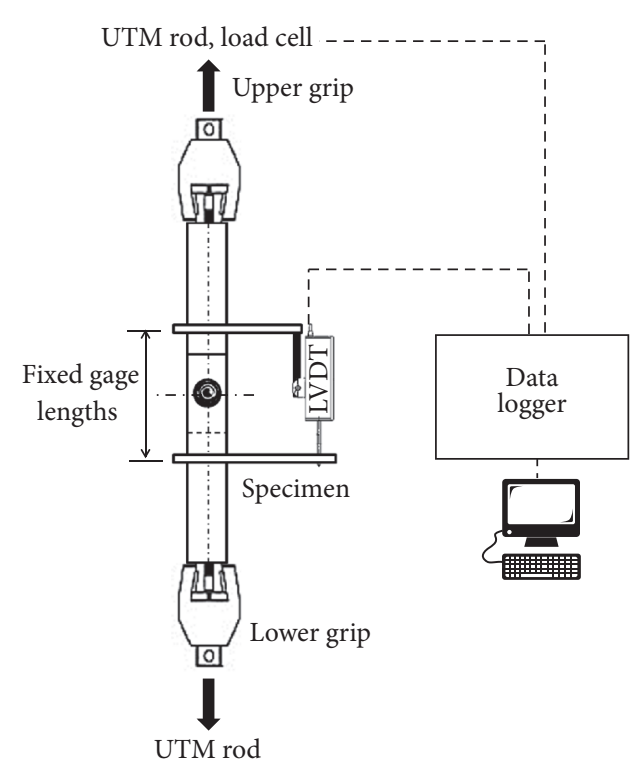

(a) Test apparatus

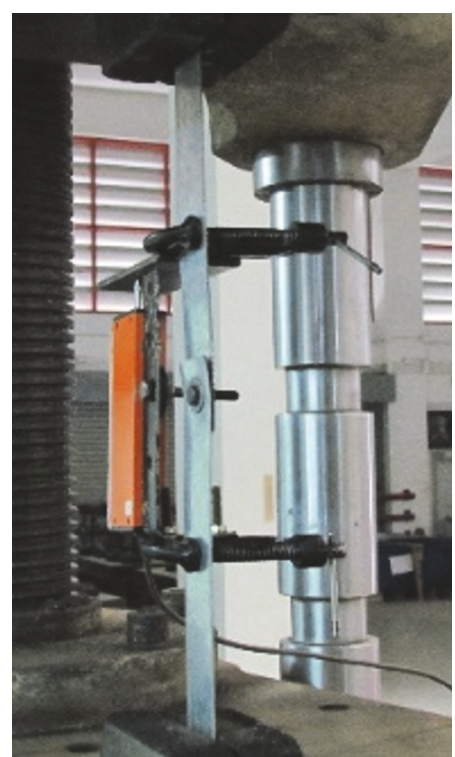

(b) Test specimen

Figure 3: Bolted connection test setup.

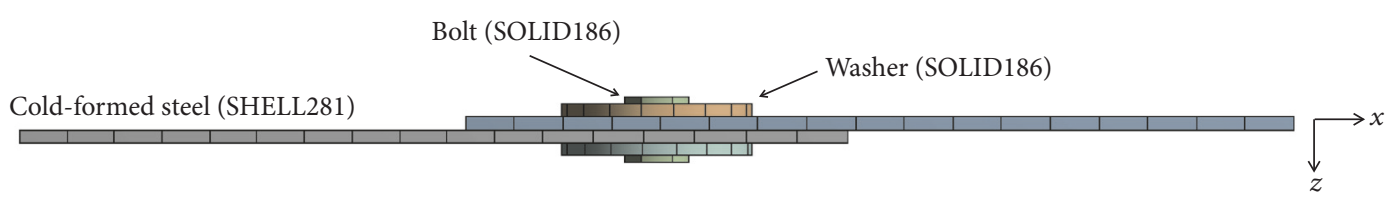

(a) Geometry model

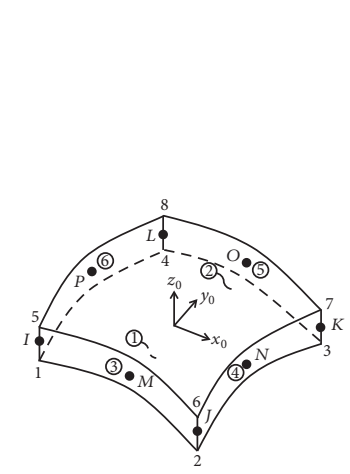

(b) SHELL281

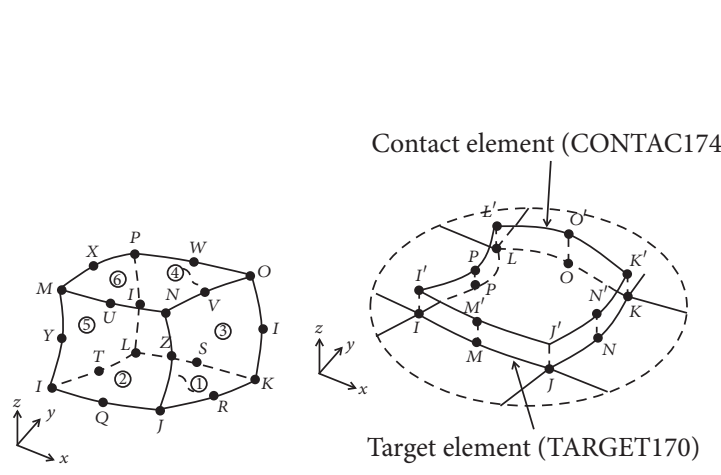

(c) SOLID186

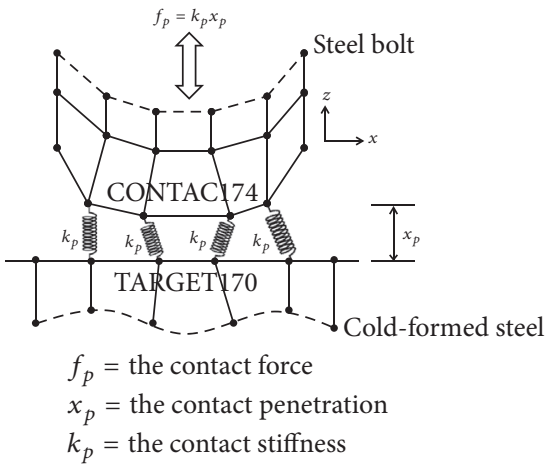

(e) Pure penalty algorithm

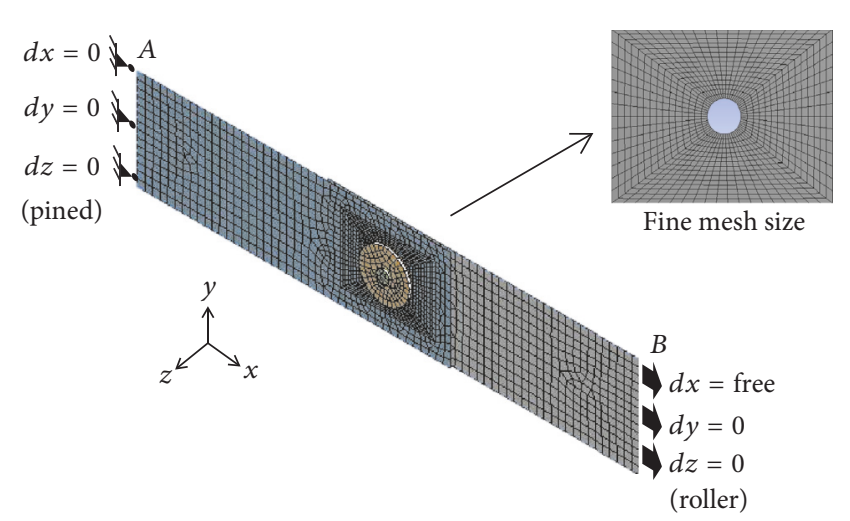

(f) Mesh and boundary condition

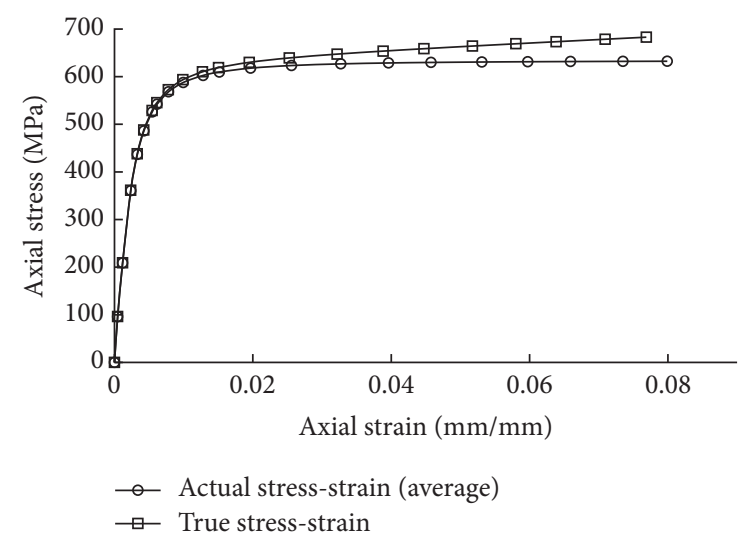

(g) Actual stress and plastic strain

FIgURE 4: Geometry, element type, and material model of FEA. 


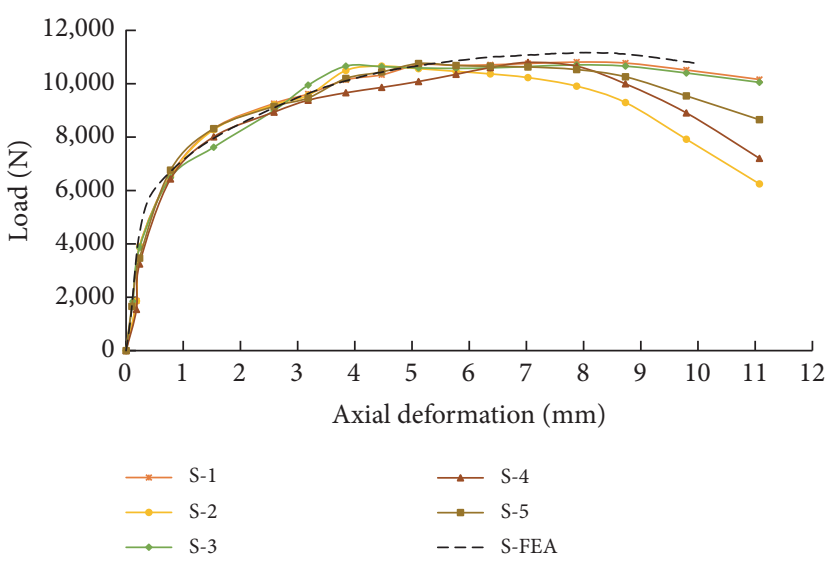

(a) Load-deformation curves

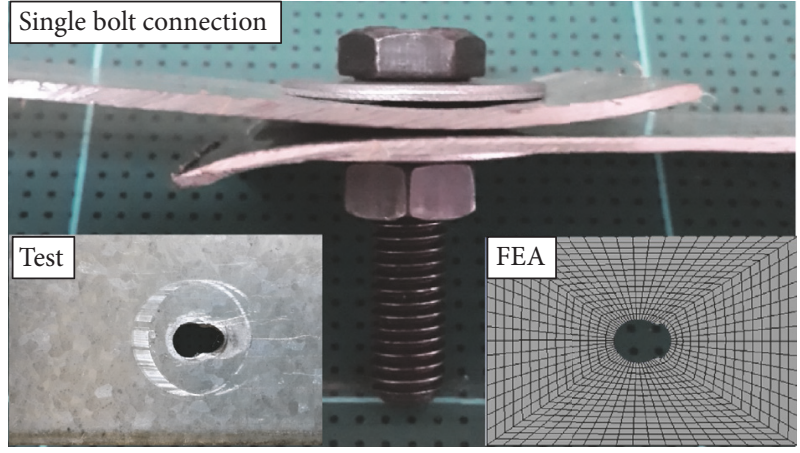

(b) Failure mode

FIGURE 5: Load-deformation curves and failure mode of single bolted connection.

TABLE 3: Summary of the lap shear connection results.

\begin{tabular}{lccc}
\hline Test & Loading capacity, $P_{n, \text { test }}(N)$ & Failure mode & $P_{n, \text { test }} / P_{n, \text { FEA }}$ \\
\hline S-1 & 10,812 & Bearing & 0.97 \\
S-2 & 10,660 & Bearing & 0.95 \\
S-3 & 10,707 & Bearing & 0.96 \\
S-4 & 10,800 & Bearing & 0.97 \\
S-5 & 10,758 & Bearing & 0.96 \\
Mean & 10,747 & & 0.96 \\
FEA & 11,167 & Bearing & \\
\hline
\end{tabular}

were performed into the nonlinear geometry analysis. Finally, the Newton-Raphson algorithm was activated to obtain the solution after each displacement increment.

\section{Single Bolt Connection Test Results}

The load capacity and failure mode of single bolt connection tests are shown in Figure 5(a). The deformation shape from the experimental tests and the FEA showed that the specimens were subjected to bearing failure as shown in Figure 5(b). The ratio of the ultimate loads between the experiment and the FEA $\left(P_{n \text {,test }} / P_{n, \text { FEA }}\right)$ is shown in Table 3 and this indicates that the ultimate load capacity of the experimental results was in good correlation with the FEA.

In order to identify the connection failure modes, the Von-Mises stress contour was normalized by the ultimate stress of the cold-formed steel material as shown in Figure 6.

Hart-Smith [14] and He and Wang [2] have suggested a method for bearing failure prediction of the shear connection. The monitoring strain point at $C, D$, and $E$ is zero when the connection suffers from bearing failure, and the monitoring stress normalization at point $C$ is equal to 1 for net-section failure. The stress-strain analysis of the FEA results showed that the lap shear bolt connection suffered from bearing failure.

\section{Bolt-Plate Interaction Stiffness Analysis}

In multibolt connections, the bolts in different rows carry different amounts of the load which depend on the bolt diameter, plate stiffness, and other geometry configurations $[15,16]$. The connection stiffness is fundamental to understanding the load transfer and the load distribution of the bolt connection. In accordance with the typical bolt, the deformation of the steel bolt, illustrated in Figure 7, was simplified as a short beam. The concept of bolt flexibility $\left(C_{b}\right)$ prediction can be defined by

$$
C_{b}=\frac{1}{k_{b}}=\frac{\delta_{b}}{F},
$$

where $k_{b}$ is the stiffness of the steel bolt, $F$ is the applied force, and $\delta_{b}$ is the bolt deformation.

An analytical beam theory with the shear deformation and rotational bending effects included is the theory known as Timoshenko beam theory [17]. For Timoshenko beams, plane cross-sections will rotate due to shear forces. The rotation $(\theta)$ and deflection of a beam $(u)$ are written by

$$
\begin{aligned}
& \theta(x)=\int_{0}^{x} \frac{M(s)}{E I} d s+\theta_{0} \\
& u(x)=\int_{0}^{x} \theta(s) d s-\int_{0}^{x} \frac{V(s)}{\kappa A G} d s+u_{0}
\end{aligned}
$$

where $V_{0}, M_{0}, \theta_{0}$, and $u_{0}$ are constants of integration which can be determined using the boundary conditions for the particular problem, $A$ is area cross-section of the beam, $G$ is a shear modulus of the beam, and $\kappa$ is the shear coefficient due to the nonuniform distribution of shear stress along the cross-section. Figure 8 shows the assumption of the load components of a steel bolt which was used to analyze the boltplate interaction stiffness. Point $A$, point $B$, and point $C$ are the reference points on the bolt that refer to the middle of the plate thickness and the bolt length.

The bolt tolerated the bearing force, shearing force, and bending moment initiated by an eccentric load from the steel 


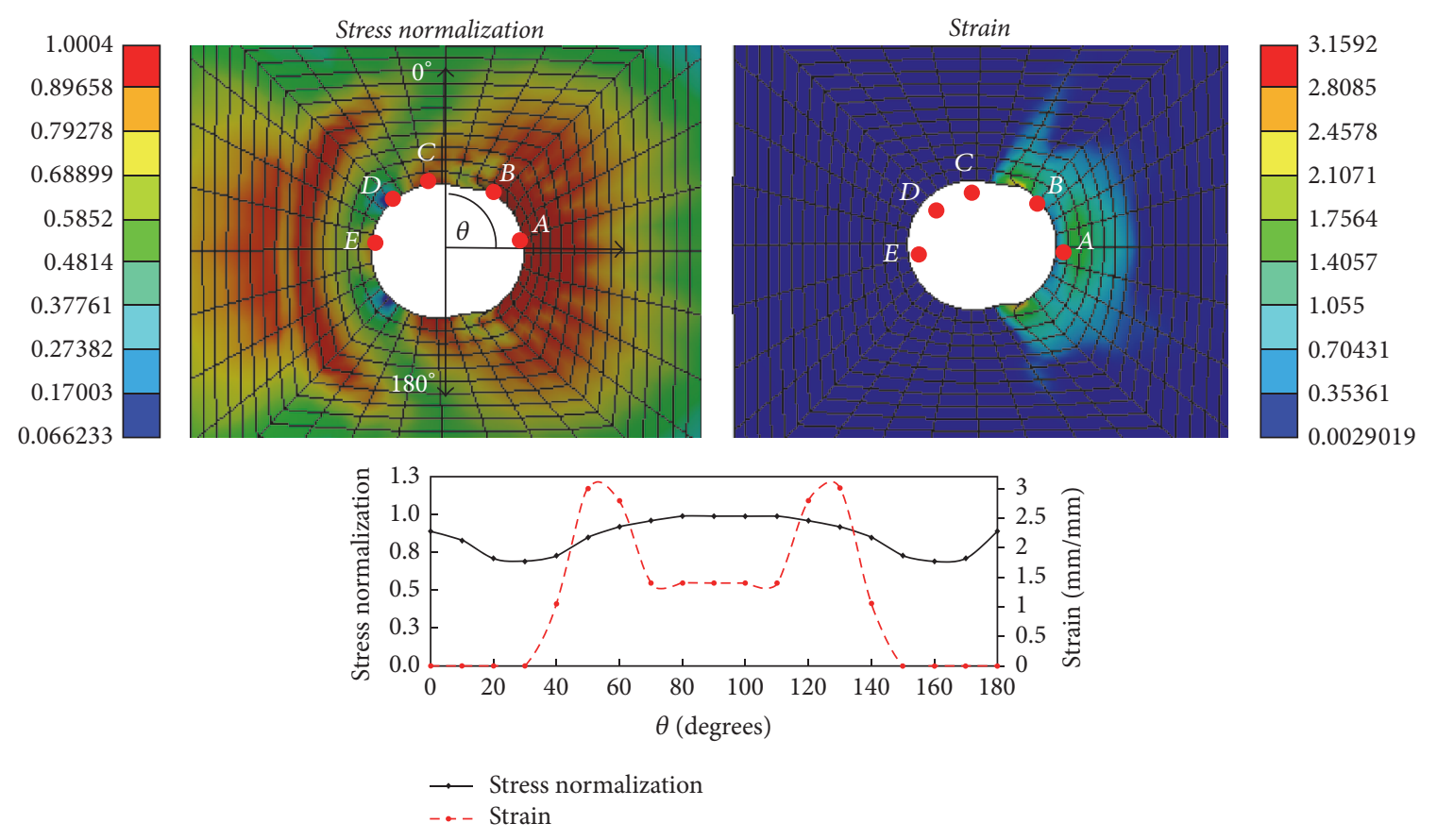

FIGURE 6: Stress normalization and strain distribution of bolt connection.

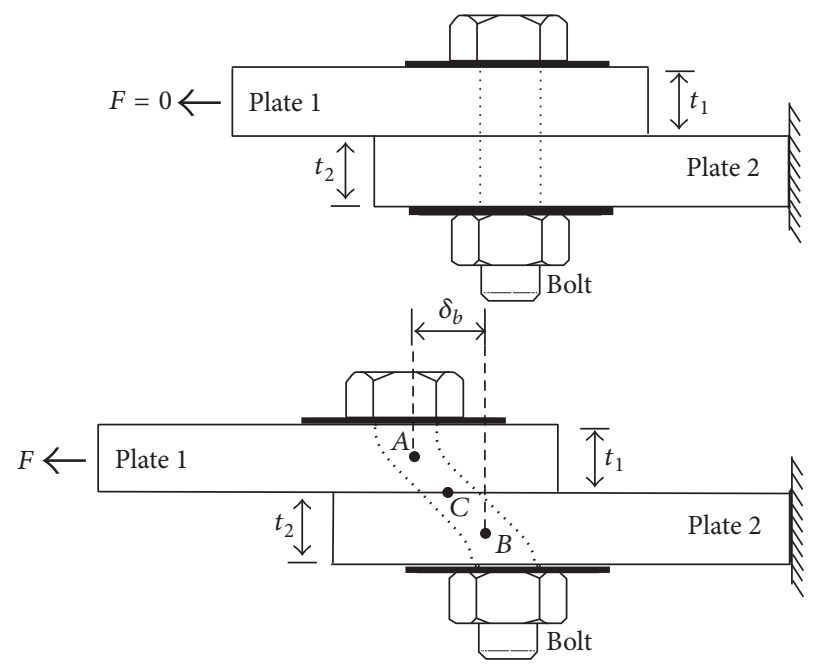

FIGURE 7: Deformation of single bolt connection.
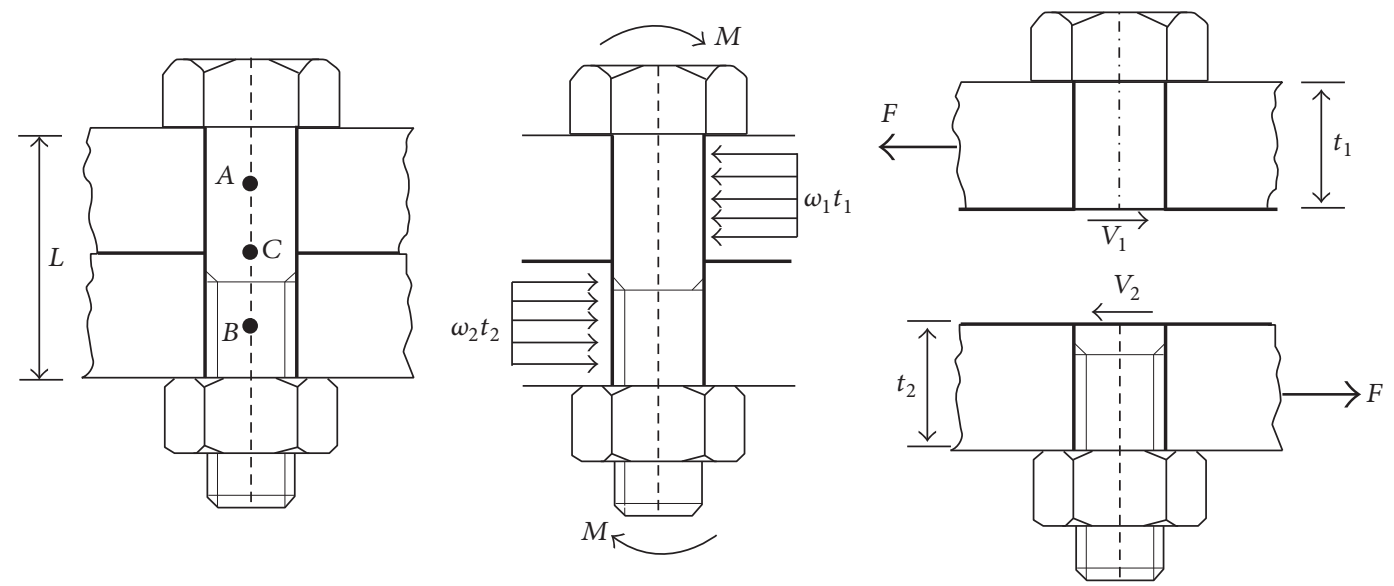

FIGURE 8: Forces in bolt. 

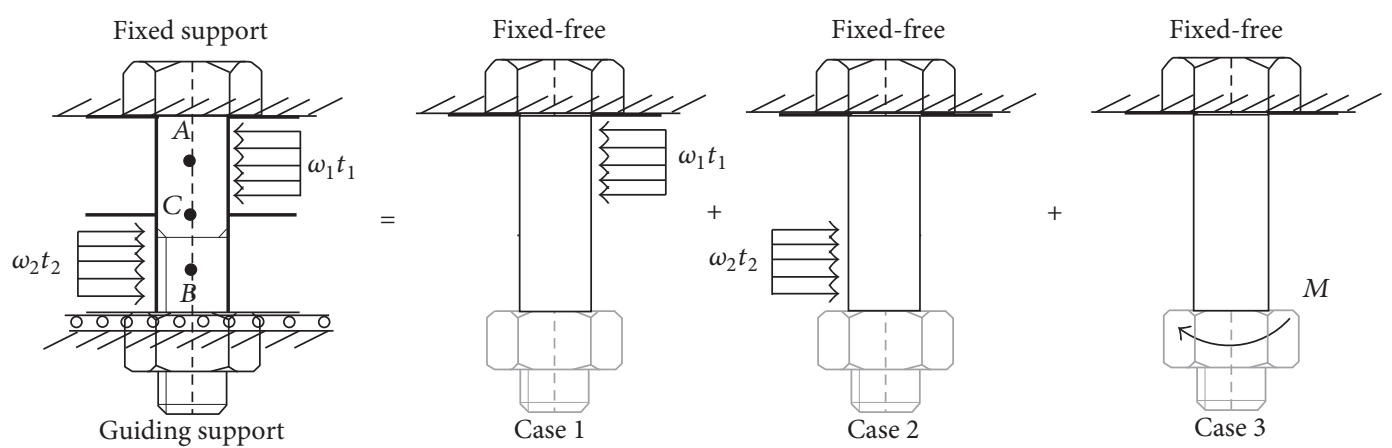

FIgURE 9: Statically indeterminate system.
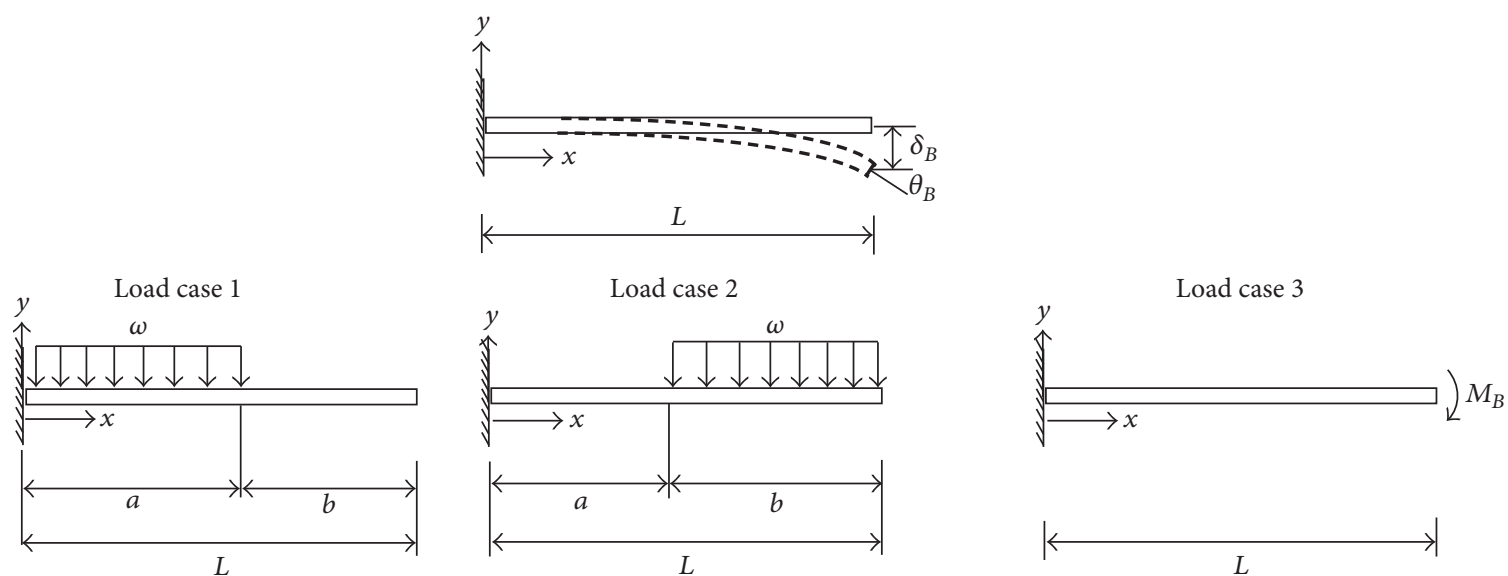

$0 \leq x \leq a$

$0 \leq x \leq a$

$\delta(x)=-\frac{\omega x^{2}}{24 E I}\left(6 a^{2}-4 a x+x^{2}\right)$

$\delta=-\frac{\omega x^{2} b}{12 E I}(3 L-2 x+3 a)$

$a \leq x \leq L$

$a \leq x \leq L$

$\delta(x)=-\frac{\omega x^{3}}{24 E I}(4 x-a)$

$\delta=-\frac{\omega}{24 E I}\left(x^{4}-4 L x^{3}+6 L^{2} x^{2}-4 a^{3} x+a^{4}\right)$

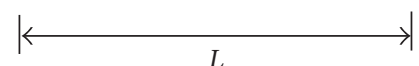

$\theta_{B}=\frac{\omega a^{3}}{6 E I}$

$\theta_{B}=\frac{\omega\left(L^{3}-a^{3}\right)}{6 E I}$

$x=L$

$\delta_{B}=-\frac{M_{B} L^{2}}{2 E I}$

$\theta_{B}=\frac{M_{B} L}{E I}$

$\delta_{B}=$ deflection at end $B$ of the beam

$\theta_{B}=$ angle of rotation at end $B$ of the beam

FiguRE 10: Bending deformation of cantilever beam.

plates. The statically indeterminate system was divided in Figure 9.

A cantilever beam with partially uniform loads and end moments idealizes the load components of a steel bolt. The superposition analysis method was used to analyze the bending deformation and shear deformation for a cantilever beam carrying a uniform load of intensity over part of the span as shown in Figures 10 and 11.

The bending moment was introduced by eccentric force from the plate. It was derived by sum of the rotation of the neutral axis at the end of the bolt as shown in Figure 12. This rotation can be rewritten by

$$
\begin{aligned}
\phi & =\phi_{1}+\phi_{2}+\phi_{3}=\left(\theta_{1}+\gamma_{1}\right)+\left(\theta_{2}+\gamma_{2}\right)+\left(\theta_{3}+\gamma_{3}\right) \\
& =0
\end{aligned}
$$

where $\theta_{1}, \theta_{2}$, and $\theta_{3}$ are the bending rotation components due to the loads $\omega_{1} t_{1}, \omega_{2} t_{2}$, and $M$, respectively. $\gamma_{1}, \gamma_{2}$, and $\gamma_{3}$ are shear rotation due to the loads $\omega_{1} t_{1}, \omega_{2} t_{2}$, and $M$, respectively.

The bending rotation and shear rotation components can be written as (5a)-(5b) which refer to Figures 10-11.

$$
\begin{aligned}
& \theta_{1}=-\frac{\omega_{1} t_{1}^{3}}{6 E_{b} I_{b}}, \\
& \theta_{2}=\frac{\omega_{2}\left(L^{3}-t_{1}^{3}\right)}{6 E_{b} I_{b}}, \\
& \theta_{3}=\frac{M_{B} L}{E_{b} I_{b}}, \\
& \gamma_{1}=0, \\
& \gamma_{2}=0, \\
& \gamma_{3}=0,
\end{aligned}
$$



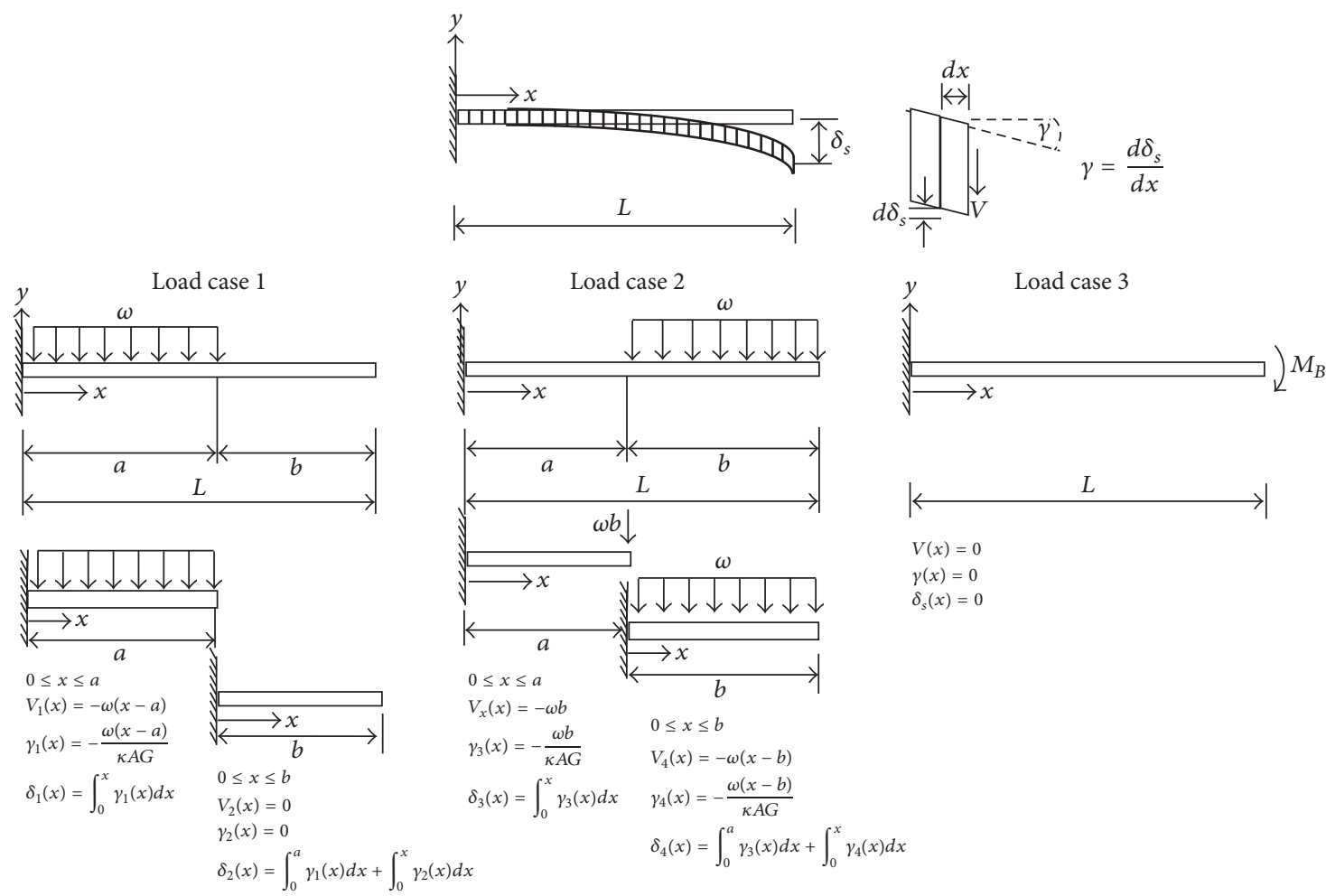

FIGURE 11: Shear deformation of cantilever beam.

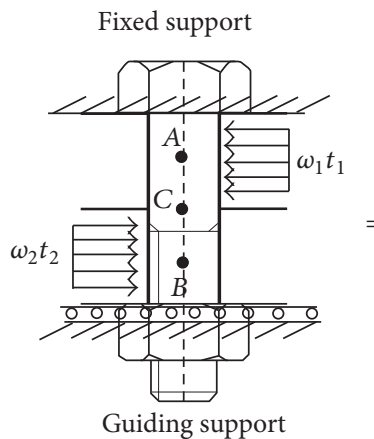

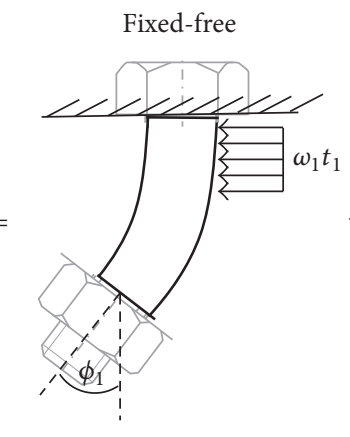

Case 1

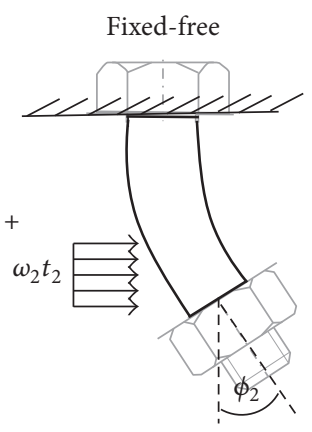

Case 2

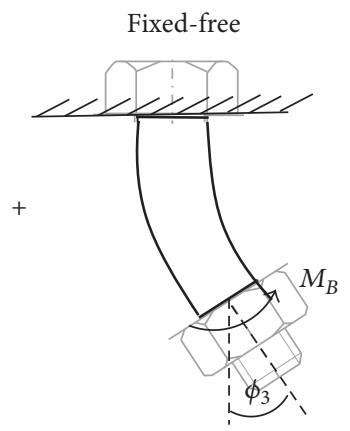

Case 3

FIGURE 12: Rotation of the bolt.

where $E_{b}$ is the modulus of elasticity of the bolt, $I_{b}$ is the moment of inertia of the bolt, $t_{1}$ and $t_{2}$ are the thickness of the plate, $\omega_{1}$ and $\omega_{2}$ are the loads on the bolt, and $L$ is the thickness of the connection. The force in the bolt $\left(F_{b}\right)$ can be presented by

$$
F_{b}=\omega_{1} t_{1}=\omega_{2} t_{2} .
$$

The relationship of the uniformed load in the connection can be written by

$$
\omega_{1}=\omega_{2}\left(\frac{t_{2}}{t_{1}}\right)
$$

Thus, (4) can be rewritten as

$$
-\frac{\omega_{1} t_{1}^{3}}{6 E_{b} I_{b}}+\frac{\omega_{2}\left(L^{3}-t_{1}^{3}\right)}{6 E_{b} I_{b}}+\frac{M_{B} L}{E_{b} I_{b}}=0 .
$$

The bending moment in the bolt can be rewritten as

$$
M_{B}=-\frac{\omega_{2}\left(\left(t_{1}+t_{2}\right)^{3}-t_{1}^{3}-t_{1}^{2} t_{2}\right)}{6\left(t_{1}+t_{2}\right)} .
$$

The connection stiffness calculation was divided into two main stiffness components being the bolt stiffness $\left(k_{b}\right)$ and the contact stiffness $\left(k_{c}\right)$ as shown in Figure 13. The bolt 

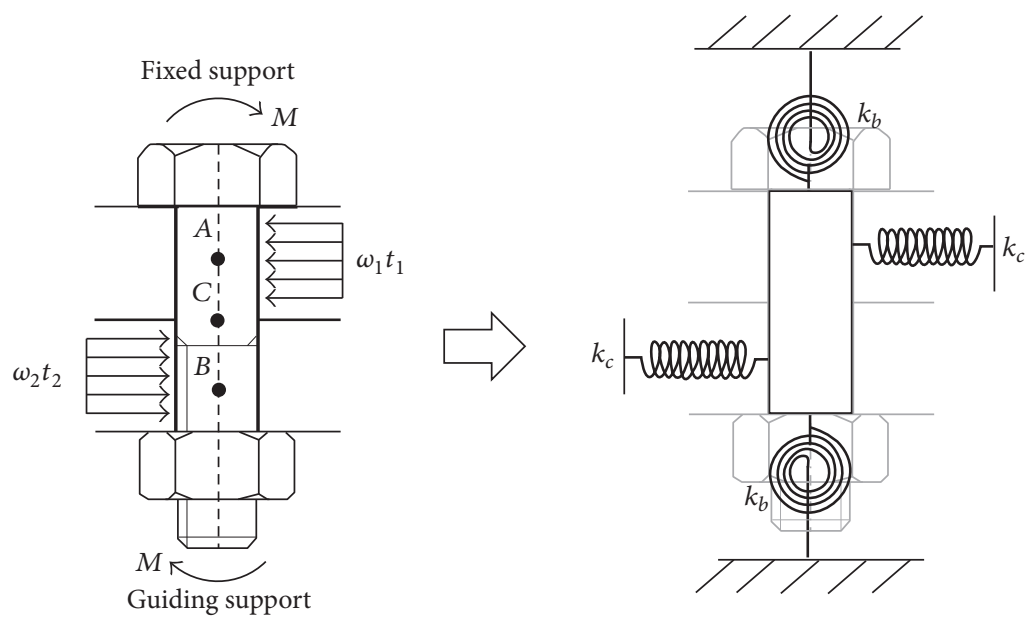

FIGURE 13: Stiffness components of single bolt connection.

stiffness was analyzed by considering the flexural stiffness $\left(k_{\text {flex, }, b}\right)$ and the shear stiffness $\left(k_{\text {she, } b}\right)$ of the bolt. The contact stiffness was the interaction stiffness between the plate and the bolt which is referred to as the plate bearing stiffness $\left(k_{\text {bea }, p}\right)$ and the bolt bearing stiffness $\left(k_{\text {bea }, b}\right)$.

The bolt-plate interaction stiffness $\left(k_{\mathrm{bp}}\right)$ is associated with the bending, shearing, and bearing stiffness of the assembly parts. It can be written as the spring components using (10a)(10b):

$$
\frac{1}{k_{\mathrm{bp}}}=\frac{1}{k_{b}}+\frac{1}{k_{c}}
$$

with

$$
\begin{aligned}
& \frac{1}{k_{b}}=\frac{1}{k_{\text {flex }, b}}+\frac{1}{k_{\text {she }, b}}, \\
& \frac{1}{k_{c}}=\frac{1}{k_{\text {bea }, p}}+\frac{1}{k_{\text {bea }, b}} .
\end{aligned}
$$

In the bending stiffness component, the bolt deformation was analyzed using ( $3 \mathrm{~b}$ ) which ignored the shear deformation term as written by (11). $\theta_{0}$ and $u_{0}$ were set equal to zero for the cantilever beam boundary condition.

$$
\begin{aligned}
u(x) & =\int_{0}^{x} \theta(s) d s+u_{0} \\
& =\int_{0}^{x}\left(\int_{0}^{x} \frac{M(s)}{E I} d s+\theta_{0}\right) d s+u_{0} .
\end{aligned}
$$

The flexural deformation of the bolt was calculated by sum of deformation at point $A$ and point $B$ as shown in Figure 14.

The flexural deformations of the bolt at point $A\left(\delta_{\text {flex }, A}\right)$ can be written as

$$
\delta_{\text {flex }, A}=\delta_{\text {flex }, A, \omega_{1} t_{1}}+\delta_{\text {flex }, A, \omega_{2} t_{2}}+\delta_{\text {flex }, A, M},
$$

where $\delta_{\text {flex, }, A, \omega_{1} t_{1}}, \delta_{\text {flex }, A, \omega_{2} t_{2}}$, and $\delta_{\text {flex }, A, M}$ are the flexural deformation at point $A$ due to $\omega_{1} t_{1}, \omega_{2} t_{2}$, and $M$, respectively, which are defined by

$$
\begin{aligned}
\delta_{\text {flex }, A, \omega_{1} t_{1}} & =-\frac{\omega_{1} t_{1}^{3}}{24 E_{b} I_{b}}\left(6 a^{2}-4 a x+x^{2}\right), \\
\delta_{\text {flex, }, A, \omega_{2} t_{2}} & =\frac{\omega_{2} b x^{2}}{12 E_{b} I_{b}}(3 L+3 a-2 x), \\
\delta_{\text {flex }, A, M} & =\frac{M(x)^{2}}{2 E_{b} I_{b}}, \\
a & =t_{1}, \\
b & =t_{2}, \\
L & =t_{1}+t_{2}, \\
x & =\frac{t_{1}}{2} .
\end{aligned}
$$

The deformations of the bolt at point $B\left(\delta_{\text {flex }, B}\right)$ can be written by

$$
\delta_{\text {flex }, B}=\delta_{\text {flex }, B, \omega_{1} t_{1}}+\delta_{\text {flex }, B, \omega_{2} t_{2}}+\delta_{\text {flex }, B, M},
$$

where $\delta_{\text {flex }, B, \omega_{1} t_{1}}, \delta_{\text {flex }, B, \omega_{2} t_{2}}$, and $\delta_{\text {flex }, B, M}$ are the flexural deformations at point $B$ due to $\omega_{1} t_{1}, \omega_{2} t_{2}$, and $M$, respectively, which are defined as

$$
\begin{aligned}
& \delta_{\text {flex }, B, \omega_{1} t_{1}}=-\frac{\omega_{1} a^{3}}{24 E_{b} I_{b}}(4 x-a), \\
& \delta_{\text {flex }, B, \omega_{2} t_{2}} \\
& \quad=\frac{\omega_{2}}{24 E_{b} I_{b}}\left(x^{4}-4 L x^{3}+6 L^{2} x^{2}-4 a^{3} x+a^{4}\right), \\
& \delta_{\text {flex }, B, M}=\frac{M(x)^{2}}{2 E_{b} I_{b}}, \\
& x=t_{1}+\frac{t_{2}}{2} .
\end{aligned}
$$




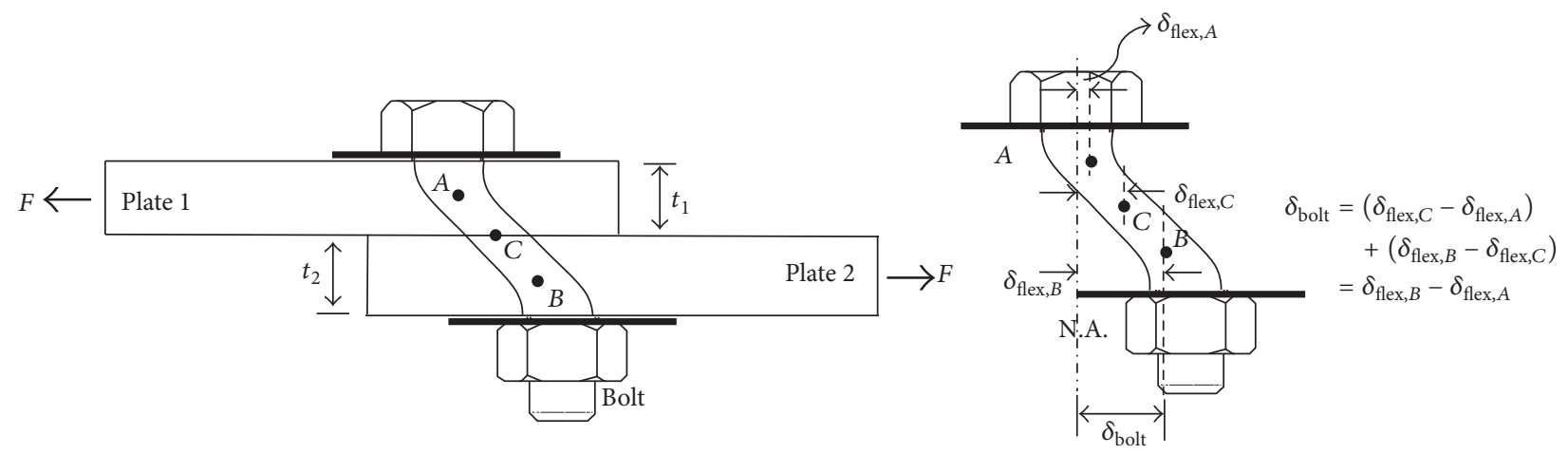

FIgURE 14: Flexural deformation of the bolt.

The total bolt flexural deformation due to $\omega_{1} t_{1}, \omega_{2} t_{2}$, and $M$ was defined using

$$
\begin{aligned}
\delta_{\text {flex }, b} & =\delta_{\text {flex }, B}-\delta_{\text {flex }, A} \\
& =\left(\frac{1}{128} \frac{\left(t_{1}+t_{2}\right)\left(3 t_{1}^{2}+13 t_{t} t_{2}+3 t_{2}^{2}\right)}{E_{b} I_{b}}\right) \omega_{2} t_{2},
\end{aligned}
$$

where $F_{b}=\omega_{2} t_{2}$. Thus, the total bolt flexural deformation can be rewritten as

$$
\delta_{\text {flex }, b}=\left(\frac{3 t_{1}^{2}+16 t_{2}^{2} t_{2}+16 t_{1} t_{2}^{2}+3 t_{2}^{3}}{128 E_{b} I_{b}}\right) F_{b} .
$$

The bolt bending flexibility $\left(C_{\mathrm{flex}, b}\right)$ is defined as the ratio of the bending deformation due to the force of the bolt which can be calculated using

$$
\begin{aligned}
C_{\text {flex }, b} & =\frac{1}{k_{\text {flex }, b}}=\frac{\delta_{\text {flex }, b}}{F_{b}} \\
& =\frac{3 t_{1}^{2}+16 t_{2}^{2} t_{2}+16 t_{1} t_{2}^{2}+3 t_{2}^{3}}{128 E_{b} I_{b}} .
\end{aligned}
$$

In the shear stiffness component, the bolt shear deformation is analyzed using (3b) in which the flexural deformation term is ignored as written by (19). $u_{0}$ is set equal to zero for the cantilever beam boundary condition.

$$
u(x)=-\int_{0}^{x} \frac{V(s)}{\kappa A G} d s+u_{0} .
$$

The Timoshenko beam theory [17] proposed that the shear stress is uniform over the cross-section. Actually, it is not uniform over the cross-section. Thus, the shear coefficient $(\kappa)$ was introduced as a correction factor to allow the nonuniform shear strain to be expressed as a constant. Hutchinson [18] proposed the shear coefficient equation of a circular cross-section using

$$
\kappa=\frac{6(1+v)^{2}}{7+12 v+4 v^{2}},
$$

where $v$ is the Poisson ratio. For $v=0.3$ for a steel bolt, the shear coefficient is 0.93 . The shear deformation of the bolt was calculated by sum of deformation at point $A$ and point $B$ as shown in Figure 15.

The deformations of the bolt at point $A\left(\delta_{s, A}\right)$ can be written using

$$
\delta_{s, A}=\delta_{s, A, \omega_{1} t_{1}}+\delta_{s, A, \omega_{2} t_{2}}+\delta_{s, A, M},
$$

where $\delta_{s, A, \omega_{1} t_{1}}, \delta_{s, A, \omega_{2} t_{2}}$, and $\delta_{s, A, M}$ are the shear deformations at point $A$ due to $\omega_{1} t_{1}, \omega_{2} t_{2}$, and $M$, respectively, which are defined using

$$
\begin{aligned}
\delta_{s, A, \omega_{1} t_{1}} & =\int_{0}^{x} \gamma_{1}(x) d x=-\frac{3 \omega_{1} t_{1}^{2}}{8 \kappa G_{b} A_{b}}, \\
\delta_{s, A, \omega_{2} t_{2}} & =\int_{0}^{x} \gamma_{3}(x) d x=\frac{\omega_{2} t_{1} t_{2}}{2 \kappa G_{b} A_{b}}, \\
\delta_{s, A, M} & =0 \\
x & =\frac{t_{1}}{2}
\end{aligned}
$$

where $A_{b}$ is the cross-sectional area of the bolt and $G_{b}$ is the shear modulus of the bolt. The deformations of the bolt at point $B\left(\delta_{B}\right)$ can be written using

$$
\delta_{s, B}=\delta_{s, B, \omega_{1} t_{1}}+\delta_{s, B, \omega_{2} t_{2}}+\delta_{s, B, M},
$$

where $\delta_{s, B, \omega_{1} t_{1}}, \delta_{s, B, \omega_{2} t_{2}}$, and $\delta_{s, B, M}$ are the shear deformation at point $B$ due to $\omega_{1} t_{1}, \omega_{2} t_{2}$, and $M$, respectively, which are defined by

$$
\begin{aligned}
\delta_{s, B, \omega_{1} t_{1}} & =\int_{0}^{a} \gamma_{1}(x) d x+\int_{0}^{x} \gamma_{2}(x) d x=-\frac{\omega_{1} t_{1}^{2}}{2 \kappa G_{b} A_{b}}, \\
\delta_{s, B, \omega_{2} t_{2}} & =\int_{0}^{a} \gamma_{3}(x) d x+\int_{0}^{x} \gamma_{4}(x) d x \\
& =\frac{\omega_{2} t_{2}\left(8 t_{1}+3 t_{2}\right)}{8 G_{b} A_{b}}, \\
\delta_{s, B, M} & =0 \\
x & =\frac{t_{2}}{2} .
\end{aligned}
$$



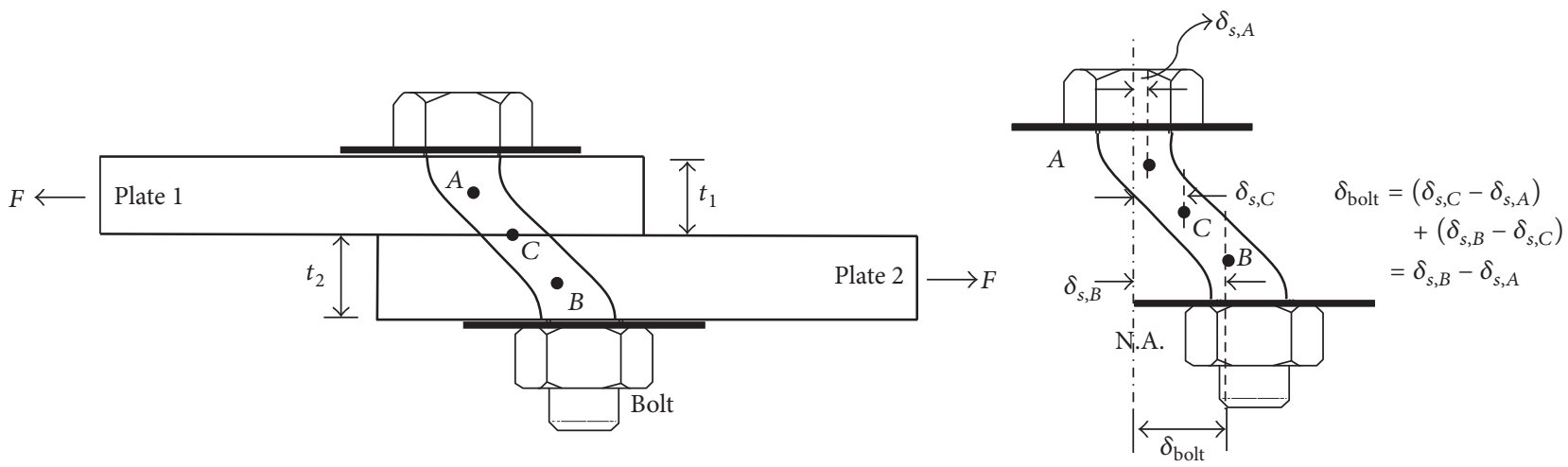

FIGURE 15: Shear deformation of the bolt.

The total bolt shear deformation due to $\omega_{1} t_{1}, \omega_{2} t_{2}$, and $M$ was defined using

$$
\delta_{s}=\delta_{s, B}-\delta_{s, A}=\frac{3}{8}\left(\frac{t_{1}+t_{2}}{\kappa A_{b} G_{b}}\right) \omega_{2} t_{2}
$$

where $\omega_{1}=\omega_{2}\left(t_{2} / t_{1}\right)$. Thus, the total bolt shear deformation can be rewritten by

$$
\delta_{s}=\frac{3}{8}\left(\frac{t_{1}+t_{2}}{\kappa A_{b} G_{b}}\right) \omega_{2} t_{2} .
$$

The bolt shear flexibility $\left(C_{\mathrm{sd}, b}\right)$ is defined as the ratio of shear deformation due to the force of the bolt which is calculated using

$$
C_{\mathrm{sd}, b}=\frac{1}{k_{\mathrm{sd}, b}}=\frac{\delta_{s}}{F_{b}}=\frac{3}{8} \frac{\left(t_{1}+t_{2}\right)}{\kappa A_{b} G_{b}} .
$$

To calculate the bearing stiffness of the bolt and plate, the bearing stiffness of connection was calculated by using the schematic diagram shown in Figure 16. The bearing stress $\left(\sigma_{\text {br }}\right)$ was defined by the applied load $(P)$ divided by the hole diameter and the plate thickness which is written as (28a). The bearing strain $\left(\varepsilon_{\mathrm{br}}\right)$ was defined by the plate bearing displacement divided by the hole diameter which is written using (28b):

$$
\begin{aligned}
\sigma_{\text {bea }} & =\frac{P}{d t}, \\
\varepsilon_{\text {bea }} & =\frac{\delta_{\text {bea }, p}}{d} .
\end{aligned}
$$

The bearing stiffness of bolt hole was calculated by using linear stress-strain relationship as presented using

$$
\begin{aligned}
& \sigma_{\text {bea }, p}=E_{p} \varepsilon_{\text {bea }, p}, \\
& k_{\text {bea }, p}=\frac{P}{\delta_{\text {bea }, p}}=\frac{t d E_{p}}{d}=t E_{p} .
\end{aligned}
$$

Similarly, the bearing stiffness of the steel bolt was calculated in the same way using the same manner which was written as

$$
\begin{aligned}
\sigma_{\text {bea }, b} & =E_{b} \varepsilon_{\text {bea }, b}, \\
k_{\text {bea }, b} & =\frac{P}{\delta_{\text {bea }, b}}=\frac{t d E_{b}}{d}=t E_{b} .
\end{aligned}
$$

Thus, the bolt bearing flexibility $\left(\mathcal{c}_{\mathrm{bea}, b}\right)$ and the plate bearing flexibility $\left(c_{\text {bea, } p}\right)$ can be calculated using

$$
\begin{aligned}
& c_{\text {bea }, b}=\frac{1}{k_{\text {bea }, b}}=\frac{1}{t_{1} E_{b}}+\frac{1}{t_{2} E_{b}}, \\
& c_{\text {bea }, p}=\frac{1}{k_{\text {bea }, p}}=\frac{1}{t_{1} E_{p, 1}}+\frac{1}{t_{2} E_{p, 2}},
\end{aligned}
$$

where $E_{p 1}$ and $E_{p 2}$ are the modulus of elasticity of plate 1 and plate 2, respectively. Finally, the bolt-plate interaction stiffness was newly proposed by the equilibrium of interaction force between the bolt and the plate which can be written using

$$
\begin{aligned}
\frac{1}{k_{\mathrm{bp}}}= & \frac{3 t_{1}^{2}+16 t_{2}^{2} t_{2}+16 t_{1} t_{2}^{2}+3 t_{2}^{3}}{128 E_{b} I_{b}}+\frac{3}{8} \frac{\left(t_{1}+t_{2}\right)}{\kappa A_{b} G_{b}} \\
& +\left(\frac{1}{t_{1} E_{b}}+\frac{1}{t_{2} E_{b}}\right)+\left(\frac{1}{t_{1} E_{p 1}}+\frac{1}{t_{2} E_{p 2}}\right) .
\end{aligned}
$$

A common method for modeling a connection stiffness association of the single bolt connection is represented by the spring model as shown in Figure 17.

The matrix equation represented a single bolt connection which can be written as

$$
\left\{\begin{array}{c}
0 \\
0 \\
F_{3}
\end{array}\right\}=\left[\begin{array}{ccc}
k_{\mathrm{bp}}+k_{p, 2} & -k_{\mathrm{bp}} & 0 \\
-k_{\mathrm{bp}} & k_{\mathrm{bp}}+k_{p, 1} & -k_{p, 1} \\
0 & -k_{p, 1} & k_{p, 1}
\end{array}\right]\left\{\begin{array}{l}
u_{1} \\
u_{2} \\
u_{3}
\end{array}\right\} .
$$

The plate stiffness was calculated in two zones as shown in Figure 17(c). The plate zone represented the plate stiffness 


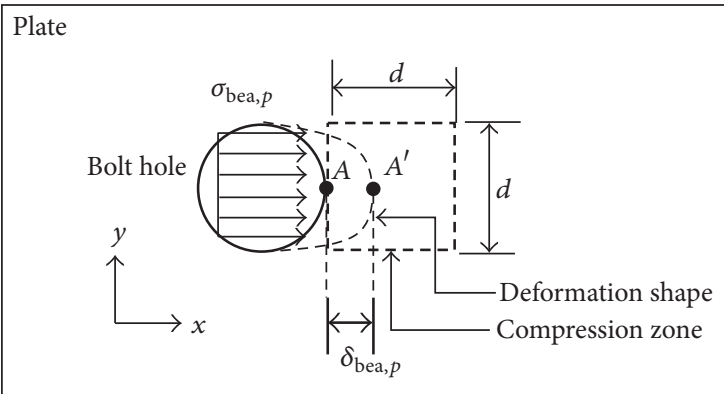

(a) Bearing deformation in the plate

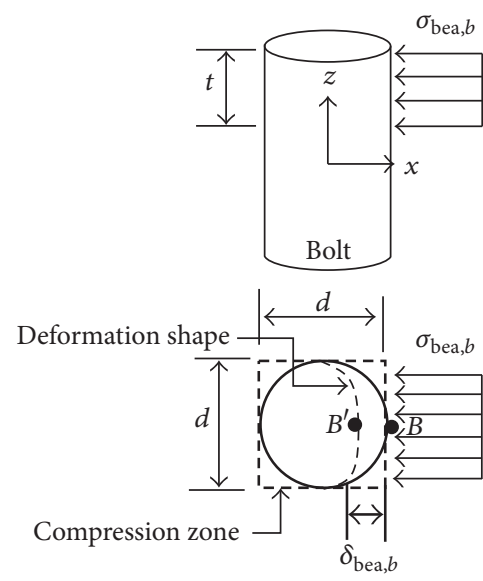

(b) Bearing deformation in the bolt

FIGURE 16: Schematic diagram of bearing deformation in the plate and bolt.

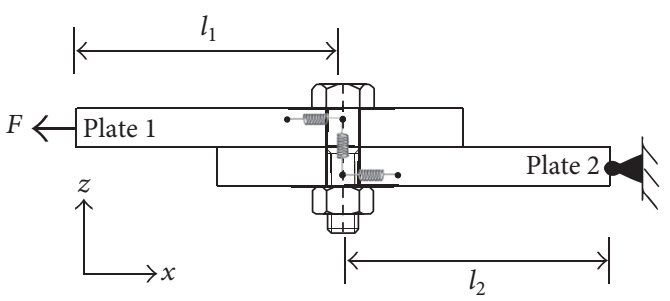

(a) Connection model

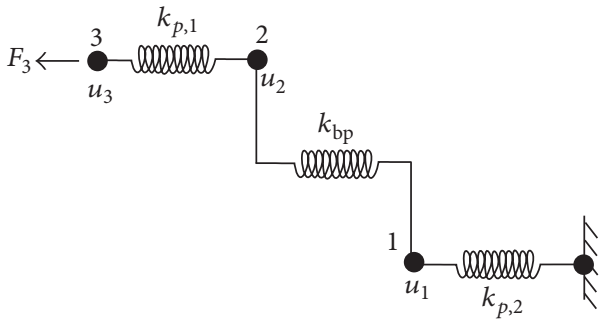

(b) Spring model

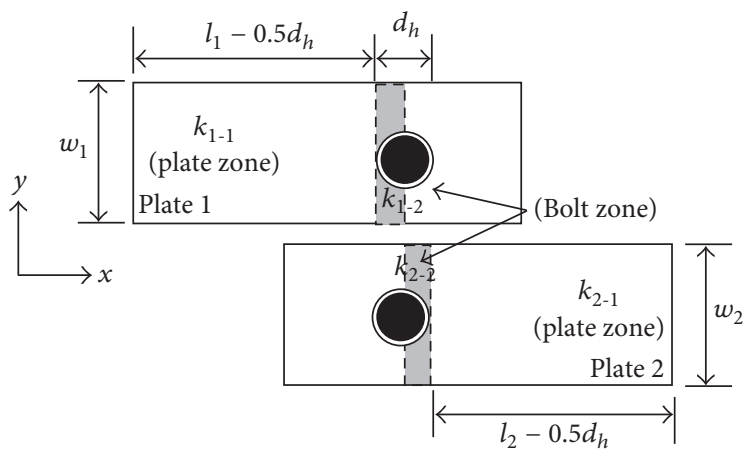

(c) Plate stiffness

FIGURE 17: The spring model of single bolt connection.

in front of the bolt. The bolt zone represented the plate stiffness alongside the bolt. The stiffness of the plate was found considering a plate subjected to uniform tensile load which is presented in Table 4.

The stiffness, load vector, and the node displacement matrix have been implemented in the Maplesoft program [19]. The load-deformation curve of node 3 was compared with a single-shear bolt connection test result which is shown in Figure 18(a). The results show that the analytical method was in good correlation with the FEA and the experimental results. Figure 18(b) shows the fastener stiffness prediction by several known semiempirical methods comparing with the proposed equation. The Grumman equation [8] is an empirically derived fastener stiffness formula that was presented by the Grumman Aerospace Corporation as given in

$$
\frac{1}{k_{\mathrm{bp}}}=\frac{\left(t_{2}+t_{1}\right)^{2}}{E_{b} d}+3.72\left(\frac{1}{t_{1} E_{p 1}}+\frac{1}{t_{2} E_{p 2}}\right) \text {. }
$$


TABLE 4: Plate stiffness.

\begin{tabular}{lccc}
\hline Stiffness & Stiffness equation & Value (N/mm) \\
$\frac{1}{k_{p, 1}}$ & $\frac{1}{k_{1-1}}+\frac{1}{k_{1-2}}=\frac{1}{\omega_{1} t_{1} E_{p, 1} /\left(l_{1}-0.5 d_{h}\right)}+\frac{1}{\left(\left(\omega_{1}-d\right) t_{1} E_{p, 1}\right) / 0.5 d_{h}}$ & $1 / 63692$ & $1 / 63692$ \\
$\frac{1}{k_{p, 2}}$ & $\frac{1}{k_{2-1}}+\frac{1}{k_{2-2}}=\frac{1}{\left(\omega_{2}-d\right) t_{2} E_{p, 2} / 0.5 d_{h}}+\frac{1}{\omega_{2} t_{2} E_{p, 2} /\left(l_{2}-0.5 d_{h}\right)}$ & $1 / 50660$ \\
$\frac{1}{k_{\mathrm{bp}}}$ & & Equation $(33)$ & \\
\hline
\end{tabular}

Remark. $k_{p, 1}$ and $k_{p, 2}$ are the plate stiffness and $E_{p, 1}$ and $E_{p, 2}$ are the modulus of elasticity of plate 1 and plate 2 .

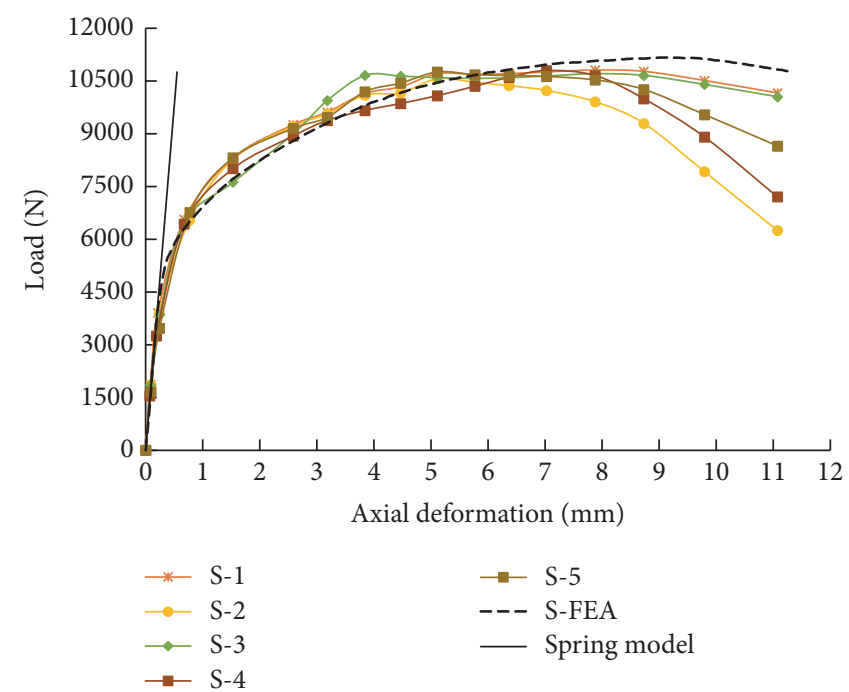

(a) Comparison with tests and FEA

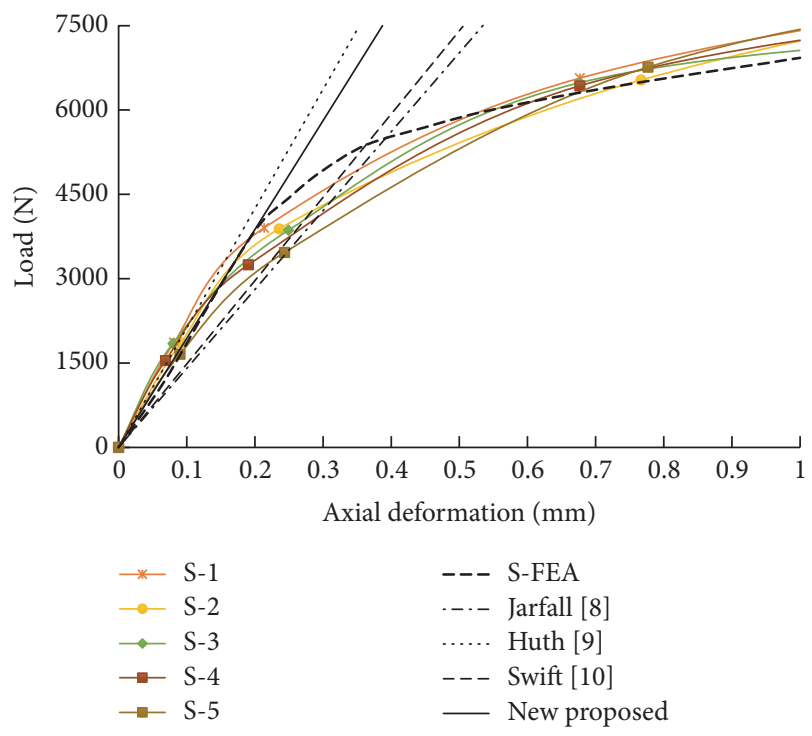

(b) Comparison with other equations

FIGURE 18: Comparison of the load-deformation curve of the proposed spring model.

The fitting equation to the load-displacement curves of the single steel bolt connection type was proposed by Huth [9] which is presented in

$$
\begin{aligned}
\frac{1}{k_{\mathrm{bp}}}= & \left(\frac{t_{2}+t_{1}}{2 d}\right)^{2 / 3} \\
& \cdot 3\left(\frac{1}{t_{1} E_{p 1}}+\frac{1}{t_{2} E_{p 2}}+\frac{1}{2 t_{1} E_{b}}+\frac{1}{2 t_{2} E_{b}}\right) .
\end{aligned}
$$

The Swift equation [10] is a flexibility empirical equation that was established based on testing data of a single-shear metallic connection as given by

$$
\begin{aligned}
\frac{1}{k_{\mathrm{bp}}} & =\frac{1.666}{0.5 d\left(\sqrt{\left(E_{L}+E_{T}\right)_{\text {plate-1 }}\left(\sqrt{E_{L}+E_{T}}\right)_{\text {plate- }}}\right)} \\
& +0.86\left(\frac{1}{\left(\sqrt{E_{L}+E_{T} t_{1}}\right)_{\text {plate-1 }}}\right. \\
& \left.+\frac{1}{\left(\sqrt{E_{L}+E_{T} t_{2}}\right)_{\text {plate-2 }}}\right) .
\end{aligned}
$$

The load comparison results showed that the stiffness values from the Grumman equation [8] and the Swift equation [10] were conservative, which does not accurately reflect the actual connection strength, especially for a single bolt connection. The Huth equation [9] matched the testing data but the shear deformation of the bolt and bending deformation of the bolt were ignored.

\section{Bolt Load Distribution Analysis}

An application of bolt-plate interaction stiffness analysis for the multibolt connection is presented by the triple bolt lap connection as in Figure 19. The structural model was assembled using the $1 \mathrm{~mm}$ thickness of cold-formed steel and a $5 \mathrm{~mm}$ diameter steel bolt. The analytical application investigated the load applied distribution among the bolt rows due to relative deformation between the top plate (plate 1) and bottom plate (plate 2).

The matrix equation representing the multibolt spring model in Figure 20 can be written as (38), and the stiffness components are presented in Table 5. 

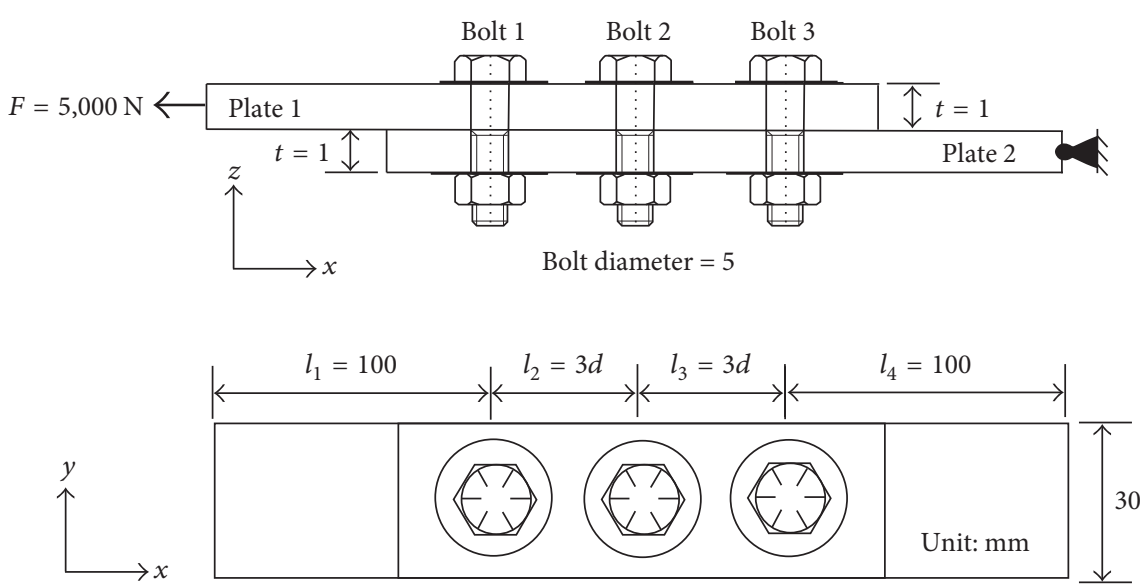

Figure 19: Multibolt connection analysis.

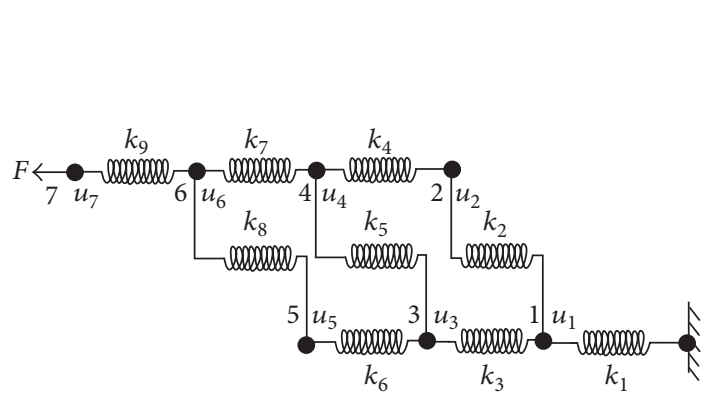

(a) Multibolt connection spring model

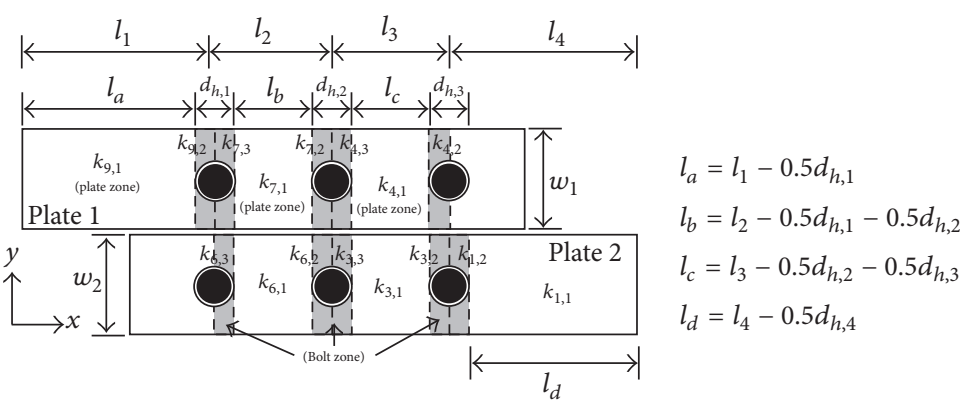

(b) Plate stiffness

FIGURE 20: The multibolt connection stiffness.

TABLE 5: Calculation of stiffness.

$$
\begin{aligned}
& \frac{1}{\frac{1}{k_{1}}}=\frac{1}{k_{1,1}}+\frac{1}{k_{1,2}} \\
& \frac{1}{k_{3}}=\frac{1}{k_{3,1}}+\frac{1}{k_{3,2}}+\frac{1}{k_{3,3}} \\
& \frac{1}{k_{4}}=\frac{1}{k_{4,1}}+\frac{1}{k_{4,2}}+\frac{1}{k_{4,3}} \\
& \frac{1}{k_{6}}=\frac{1}{k_{6,1}}+\frac{1}{k_{6,2}}+\frac{1}{k_{6,3}} \\
& \frac{1}{k_{7}}=\frac{1}{k_{7,1}}+\frac{1}{k_{7,2}}+\frac{1}{k_{7,3}} \\
& \frac{1}{k_{9}}=\frac{1}{k_{9,1}}+\frac{1}{k_{9,2}} \\
& \frac{1}{k_{2}}, \frac{1}{k_{5}}, \frac{1}{k_{8}}
\end{aligned}
$$
Stiffness component

$$
k_{1,1}=\frac{\omega_{2} t_{2} E_{p 2}}{l_{d}}, k_{1,2}=\frac{\left(\omega_{2}-d_{h, 3}\right) t_{2} E_{p 2}}{0.5 d_{h, 3}}
$$$$
k_{3,1}=\frac{\omega_{2} t_{2} E_{p 2}}{l_{c}}, k_{3,2}=\frac{\left(\omega_{2}-d_{h, 3}\right) t_{2} E_{p 2}}{0.5 d_{h, 3}}, k_{3,3}=\frac{\left(\omega_{2}-d_{h, 2}\right) t_{2} E_{p 2}}{0.5 d_{h, 2}}
$$$$
k_{4,1}=\frac{\omega_{1} t_{1} E_{p 1}}{l_{c}}, k_{4,2}=\frac{\left(\omega_{1}-d_{h, 3}\right) t_{1} E_{p 1}}{0.5 d_{h, 3}}, k_{4,3}=\frac{\left(\omega_{1}-d_{h, 2}\right) t_{1} E_{p 1}}{0.5 d_{h, 2}}
$$$$
k_{6,1}=\frac{\omega_{2} t_{2} E_{p 2}}{l_{b}}, k_{6,2}=\frac{\left(\omega_{2}-d_{h, 2}\right) t_{2} E_{p 2}}{0.5 d_{h, 2}}, k_{6,3}=\frac{\left(\omega_{2}-d_{h, 1}\right) t_{2} E_{p 2}}{0.5 d_{h, 1}}
$$$$
k_{7,1}=\frac{\omega_{1} t_{1} E_{p 1}}{l_{b}}, k_{7,2}=\frac{\left(\omega_{1}-d_{h, 2}\right) t_{1} E_{p 1}}{0.5 d_{h, 2}}, k_{7,3}=\frac{\left(\omega_{1}-d_{h, 1}\right) t_{1} E_{p 1}}{0.5 d_{h, 1}}
$$$$
k_{9,1}=\frac{\omega_{1} t_{1} E_{p 1}}{l_{a}}, k_{9,2}=\frac{\left(\omega_{1}-d_{h, 1}\right) t_{1} E_{p 1}}{0.5 d_{h, 1}}
$$

Equation (33)

Remark. $k_{1}$ and $k_{9}$ are the stiffness of the plate from the bolt to the ends of plates, $k_{3}, k_{4}, k_{6}$, and $k_{7}$ are the stiffness of the plate between bolts, and $k_{2}, k_{5}$, and $k_{8}$ are the bolt-plate interaction stiffness. 


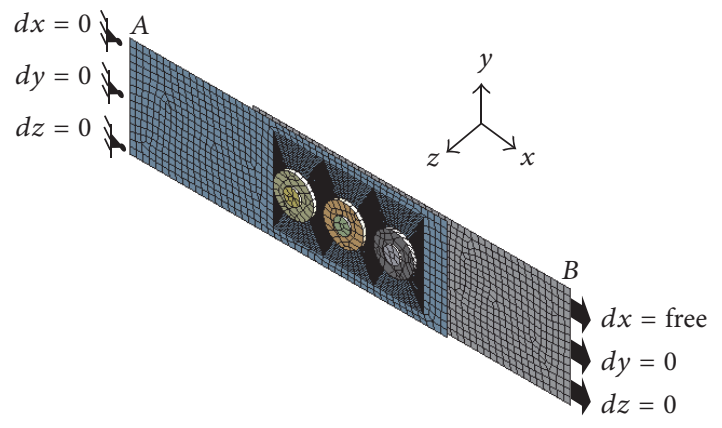

(a) Finite element model of triple bolt connection

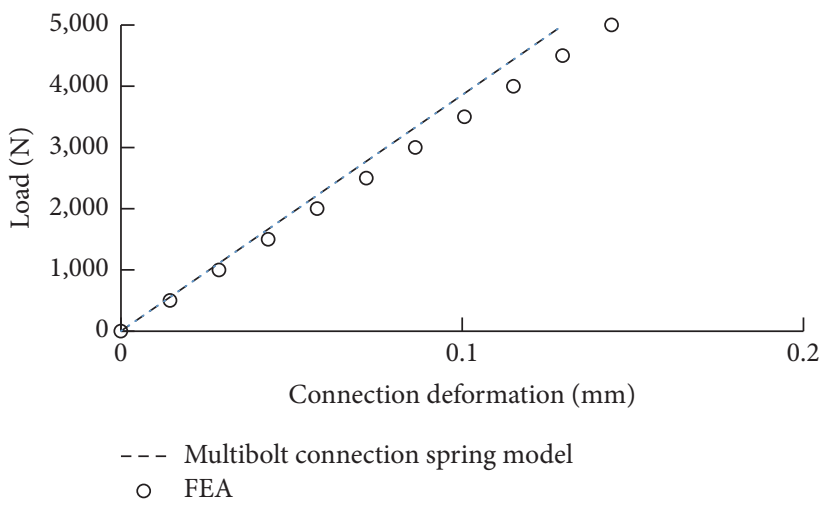

(b) Connection load

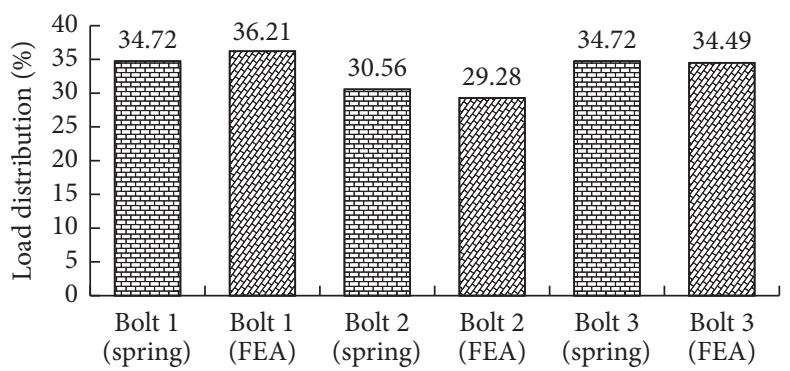

(c) Load distribution

FIGURE 21: Connection load and load distribution of analytical model and FEA.

$$
\left\{\begin{array}{l}
0 \\
0 \\
0 \\
0 \\
0 \\
0 \\
F
\end{array}\right\}=\left[\begin{array}{ccccccc}
k_{1}+k_{2}+k_{3} & -k_{2} & -k_{3} & 0 & 0 & 0 & 0 \\
-k_{2} & k_{2}+k_{4} & 0 & -k_{4} & 0 & 0 & 0 \\
-k_{3} & 0 & k_{3}+k_{5}+k_{6} & -k_{5} & -k_{6} & 0 & 0 \\
0 & -k_{4} & -k_{5} & k_{4}+k_{5}+k_{7} & 0 & -k_{7} & 0 \\
0 & 0 & -k_{6} & 0 & k_{6}+k_{8} & -k_{8} & 0 \\
0 & 0 & 0 & -k_{7} & -k_{8} & k_{7}+k_{8}+k_{9} & -k_{9} \\
0 & 0 & 0 & 0 & 0 & -k_{9} & k_{9}
\end{array}\right]\left\{\begin{array}{l}
u_{1} \\
u_{2} \\
u_{3} \\
u_{4} \\
u_{5} \\
u_{6} \\
u_{7}
\end{array}\right\} .
$$

The nodal deformation was calculated by inverting the stiffness matrix and multiplying by the load vector. The carried bolt load $(P)$ was calculated using

$$
\begin{aligned}
& P_{1}=K_{8}\left(u_{6}-u_{5}\right), \\
& P_{2}=K_{5}\left(u_{4}-u_{3}\right), \\
& P_{3}=K_{2}\left(u_{2}-u_{1}\right) .
\end{aligned}
$$

To validate the analytical model, the finite element model was generated for comparison with the analytical result as shown in Figure 21(a). An analysis was performed in which material failure was not involved in the study. Thus, the small applied load was modeled using a finite element model to investigate the load distribution behavior. The validation of the analytical model results is presented in Figure 21(b). The connection load and load distribution indicated by the analytical model were in good agreement with the FEA. The load distribution results in Figure 21(c) have been expressed as a percentage of the total connection load $(F)$. It can be seen that the load was shared unevenly between each bolt. The uneven load distribution in the triple bolt connection was analyzed using the parametric study.

\section{The Parametric Study of Multibolt Connection}

The analytical spring model as in the previous section was used to examine the effects of various connection parameters. The parametric study calculated the load distribution of the bolt connection with variations in the bolt diameters, plate thickness $\left(t_{1}=t_{2}\right)$, and the plate thickness ratio $\left(t_{2} / t_{1}\right)$. The 


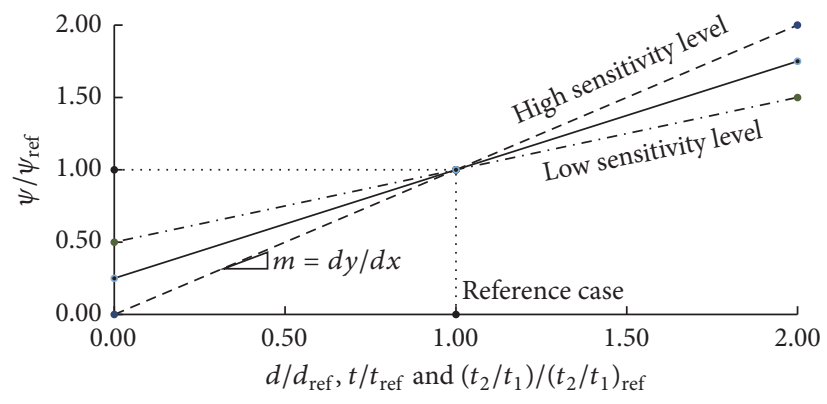

FIGURE 22: Concept of the sensitivity analysis.

geometry model and the load condition as in the previous section were adapted in the parametric study. The efficiency $(\psi)$ of the load distribution of multibolt connection was proposed shown in

$$
\psi=\frac{n P_{\min }}{\sum_{i=1}^{n} P_{i}}, \quad \text { for } i=1,2,3, \ldots, n,
$$

where $P_{i}$ is the bolt load in the $i$-th row, $P_{\min }$ is the smallest load in the bolts, and $n$ is the number of rows in the connection. Sensitivity analysis investigated these potential changes and their impacts on inferences to be obtained from the analytical model. The conception of sensitivity analysis is presented in Figure 22. The slope of the normalized efficiency graph with respect to changes in the geometric parameter was used to measure the sensitivity level. A steeper graph indicates a higher sensitivity level while a gentler slope indicates a lower sensitivity level. In each case study, the efficiency graph was normalized by the reference value. The reference cases involved bolt diameter of $8 \mathrm{~mm}$, plate thickness of $1.0 \mathrm{~mm}$, and $t_{2} / t_{1}$ of 3.0 which are used to analyze the sensitivity of variation in the bolt diameter, plate thickness, and $t_{2} / t_{1}$ sensitivity, respectively.

Variation in the bolt diameter introduced efficiency of load distribution shown in Table 6 and Figure 23(a). Increasing the bolt diameter had a significant effect on the load distributions in a multibolt connection. The change in the bolt diameter affected the proportion of the boltplate interaction stiffness between the bolt and plates which resulted in an even load distribution.

The efficiency of bolt load distribution had small changes with increased plate thickness as shown in Table 7 and Figure 24(a). The bolt-plate interaction stiffness and axial stiffness of the plates were related to the plated thickness, as a change in the plate thickness produced an equal change in the bolt-plate interaction stiffness and the axial stiffness which slightly changed the efficiency of load distribution.

The efficiency of load distributions was changed suddenly with changes to the $t_{2} / t_{1}$ ratio as shown in Table 8 and Figure 25(a).

The efficiency of load distribution decreased when the $t_{2} / t_{1}$ ratio was greater than 1 , but the carried load for the first bolt row increasingly changed. Once the $t_{2} / t_{1}$ ratio was greater than $1\left(t_{2} / t_{1} \gg 1\right)$, the behavior of plate 2 was established as a rigid bar as shown in Figure 26. The steel bolt was constrained by the axial stiffness of plate 2 which
TABLE 6: Bolt load distribution for variation in bolt diameter.

\begin{tabular}{lcccc}
\hline \multirow{2}{*}{$d(\mathrm{~mm})$} & \multicolumn{3}{c}{ Bolt load distribution (\%) } & \multirow{2}{*}{ Efficiency, $\psi(\%)$} \\
& Bolt 1 & Bolt 2 & Bolt 3 & \\
\hline 4 & 34.99 & 30.03 & 34.99 & 90.09 \\
6 & 34.53 & 30.95 & 34.53 & 92.84 \\
8 & 34.27 & 31.46 & 34.27 & 94.37 \\
10 & 34.11 & 31.78 & 34.11 & 95.33 \\
12 & 34.00 & 32.00 & 34.00 & 95.99
\end{tabular}

Remark. $t_{1}$ and $t_{2}=1 \mathrm{~mm}$ and $l_{1}$ and $l_{4}=100 \mathrm{~mm}$.

was simulated as a semi-fixed support condition. Then, bolt 1 could not transfer the load before bearing failure or shearing of the bolt failure occurred.

From the parametric study results, it was clear that varying the geometries influenced the connection stiffness, which significantly affected the load distribution. The sensitivity analysis results of the multibolt connection from variation in the bolt diameter, plate thickness, and $t_{2} / t_{1}$ are shown in Figures 23(b), 24(b), and 25(b). The sensitivity value was $0.0605,0.0136$, and -0.0646 for the bolt diameter, plate thickness, and $t_{2} / t_{1}$ sensitivity, respectively. The variation in $t_{2} / t_{1}$ showed high sensitivity with the triple bolt connection, with sudden decay when $t_{2} / t_{1}>1$. Thus, differences in the plate thickness should be emphasized in the connection design.

\section{Conclusion}

The bolt load distribution efficiency of a cold-formed steel, multibolt connection was presented. The analytical precedence with a spring model was used to simplify the stiffness of the bolt connection. A new bolt-plate interaction stiffness equation was proposed which was verified by the FEA and experimental tests. The spring model with bolt-plate interaction stiffness was used to estimate the bolt load distribution of the multibolt connection. The results showed that the analytical model was accurate and had good correlation with the FEA. Furthermore, the analytical procedure was used to examine the efficiency of load distribution for the multibolt connection and these results showed an uneven sharing of the load among bolts with one of them carrying the major component of the load. Thus, the stress distribution of the major load carrying hole resulted in high-stress 

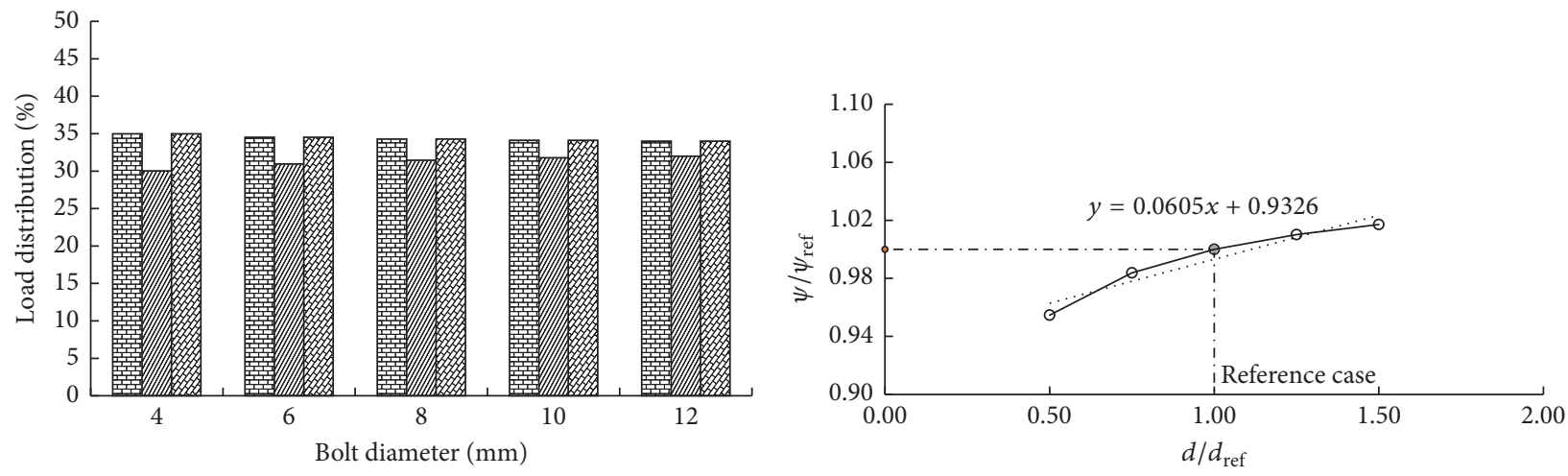

圆 Bolt 1

Bolt 2

夙 Bolt 3
(a) Bolt load distribution
(b) Parameter sensitivity

FIGURE 23: Bolt load distribution and sensitivity analysis results of varying bolt diameters.
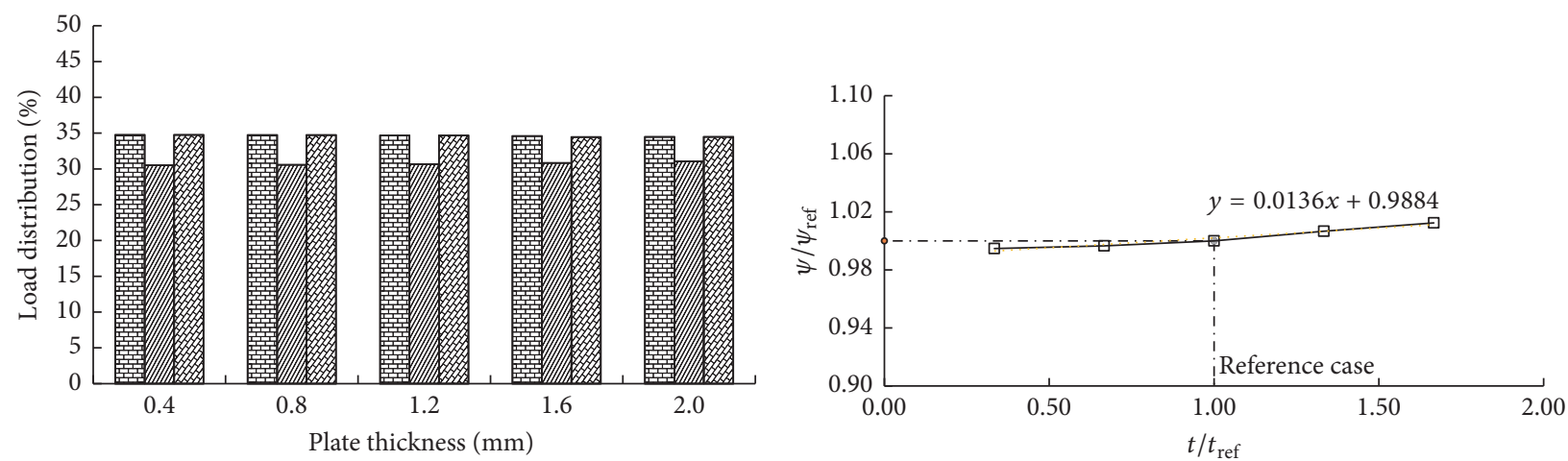

葍 Bolt 1

Bolt 2

阴烈 Bolt 3
(a) Bolt load distribution
(b) Parameter sensitivity

FIGURE 24: Bolt load distribution and sensitivity analysis results of varying plate thickness.
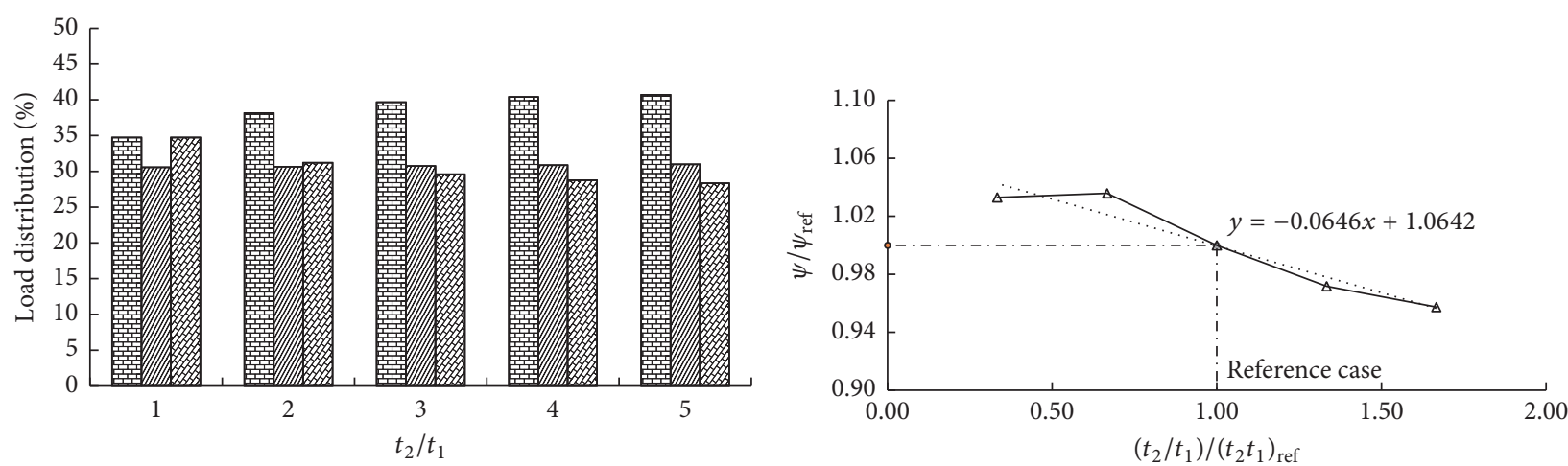

凅 Bolt 1

Bolt 2

四前 Bolt 3

(a) Bolt load distribution

(b) Parameter sensitivity

FIGURE 25: Bolt load distribution and sensitivity analysis results of the plate thickness ratio $\left(t_{2} / t_{1}\right)$. 


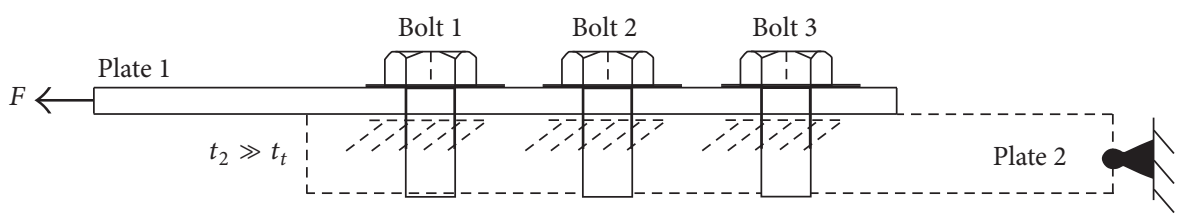

FIgURE 26: Effect of the $t_{2} / t_{1}$ ratio more than $1(\gg 1)$ to the steel bolts.

TABLE 7: Bolt load distribution for variation in plate thickness.

\begin{tabular}{|c|c|c|c|c|}
\hline \multirow{2}{*}{$t_{1}$ and $t_{2}(\mathrm{~mm})$} & \multicolumn{3}{|c|}{ Bolt load distribution (\%) } & \multirow{2}{*}{ Efficiency, $\psi(\%)$} \\
\hline & Bolt 1 & Bolt 2 & Bolt 3 & \\
\hline 0.40 & 34.75 & 30.51 & 34.75 & 91.52 \\
\hline 0.60 & 34.72 & 30.56 & 34.72 & 91.69 \\
\hline 1.00 & 34.67 & 30.67 & 34.67 & 92.01 \\
\hline 1.40 & 34.59 & 30.83 & 34.44 & 92.62 \\
\hline 1.60 & 34.48 & 31.05 & 34.48 & 93.14 \\
\hline
\end{tabular}

Remark. $l_{1}$ and $l_{4}=100 \mathrm{~mm}, l_{2}$ and $l_{3}=15 \mathrm{~mm}, \omega=30 \mathrm{~mm}$, and $d=5 \mathrm{~mm}$.

TABLE 8: Bolt load distribution for variation in plate thickness ratio $\left(t_{2} / t_{1}\right)$.

\begin{tabular}{lcccc}
\hline \multirow{2}{*}{$t_{2} / t_{1}$} & \multicolumn{3}{c}{ Bolt load distribution (\%) } & \multirow{2}{*}{ Efficiency, $\psi(\%)$} \\
\hline 1 & Bolt 1 & Bolt 2 & Bolt 3 & \\
2 & 34.72 & 30.56 & 34.72 & 91.69 \\
3 & 38.14 & 30.65 & 31.21 & 91.95 \\
4 & 39.67 & 30.75 & 29.59 & 88.76 \\
5 & 40.39 & 30.86 & 28.75 & 86.25 \\
\hline
\end{tabular}

Remark. $t_{1}=1 \mathrm{~mm}, l_{1}$ and $l_{4}=100 \mathrm{~mm}, l_{2}$ and $l_{3}=15 \mathrm{~mm}$, and $d=5 \mathrm{~mm}$.

concentration which caused weakness in the mechanically fastened connection. Moreover, increasing $t_{2} / t_{1}$ had a greater influence on the load distribution and efficiency of a multibolt connection than changing the bolt diameter and plate thickness. The results of the study indicate that the practical design procedures with assuming equal load distribution among the bolts may not be conservative because some components may be failed before the connection develops the full plastic strength. Finally, the proposed procedure can be used together with the conventional design of the bolt connection to get insight into the more realistic load distribution.

\section{Conflicts of Interest}

The authors declare that they have no conflicts of interest.

\section{Acknowledgments}

The authors wish to acknowledge the Kasetsart University Research and Development Institute (KURDI) for providing funding support and BlueScope Lysaght (Thailand) Limited for material support.

\section{References}

[1] Y. Cai and B. Young, "Structural behavior of cold-formed stainless steel bolted connections," Thin-Walled Structures, vol. 83, pp. 147-156, 2014.

[2] Y. C. He and Y. C. Wang, "Load-deflection behavior of thinwalled plates with multiple bolts in shearing," Thin-Walled Structures, vol. 55, pp. 51-63, 2012.

[3] F. R. Liu, L. B. Zhao, S. Mehmood, J. Y. Zhang, and B. J. A. Fei, "A modified failure envelope method for failure prediction of multi-bolt composite joints," Composites Science and Technology, vol. 83, pp. 54-63, 2013.

[4] J. Y. Zhang, F. R. Liu, L. B. Zhao, and B. J. Fei, "A novel characteristic curve for failure prediction of multi-bolt composite joints," Composite Structures, vol. 108, no. 1, pp. 129-136, 2014.

[5] J. Zhang, F. Liu, L. Zhao, Y. Chen, and B. Fei, "A progressive damage analysis based characteristic length method for multibolt composite joints," Composite Structures, vol. 108, no. 1, pp. 915-923, 2014.

[6] J. Henriques, J.-P. Jaspart, and L. S. da Silva, "Ductility requirements for the design of bolted lap shear connections in bearing," Advanced Steel Construction, vol. 10, no. 1, pp. 33-52, 2014.

[7] G. L. Kulak, J. W. Fisher, and J. H. Struik, A Guide to Design Criteria for Bolted and Riveted Joints \& Sons, New York, NY, USA, 1987.

[8] L. Jarfall, "Shear loaded fastener installations, Report KH R3360," Tech. Rep., Saab-Scania, Sweden, 1983.

[9] H. Huth, "Influence of fastener flexibility on the prediction of load transfer and fatigue life for multiple-row joints," Symposia Papers STPs ASTM STP927-EB, pp. 221-250, 1986.

[10] T. Swift, "Repair to damage tolerant aircraft," in Proceedings of the International Symposium on the Structural Integrity of Aging Airplane, Atlanta, GA, USA, 1990.

[11] ASTM A370-07b, Standard Test Methods and Definitions for Mechanical Testing of Steel Products, American Society for Testing and Materials (ASTM), West Conshohocken, PA, USA, 2007.

[12] ASTM A325M, High strength bolts for structural steel joints [Metric], American Society for Testing and Materials (ASTM), West Conshohocken, PA, USA, 1994.

[13] ANSYS, ANSYS user's manual. Revision 15, ANSYS, Inc., Canonsburg, PA, USA, 2014.

[14] L. J. Hart-Smith, "Bonded-bolted composite joints," Journal of Aircraft, vol. 22, no. 11, pp. 993-1000, 1985.

[15] V. P. Lawlor, M. A. McCarthy, and W. F. Stanley, "An experimental study of bolt-hole clearance effects in double-lap, multi-bolt composite joints," Composite Structures, vol. 71, no. 2, pp. 176190, 2005.

[16] L. Feo, G. Marra, and A. S. Mosallam, "Stress analysis of multi-bolted joints for FRP pultruded composite structures," Composite Structures, vol. 94, no. 12, pp. 3769-3780, 2012. 
[17] S. P. Timoshenko, "On the correction for shear of the differential equation for transverse vibrations of prismatic bars," Philosophical Magazine, vol. 41, no. 245, pp. 744-746, 1922.

[18] J. R. Hutchinson, "Shear coefficients for Timoshenko beam theory," Journal of Applied Mechanics, vol. 68, no. 1, pp. 87-92, 2000.

[19] L. Bernardin, P. Chin, P. DeMarco et al., Maple Programming Guide, Maple Inc., Waterloo, Ontario, Canada, 2012. 


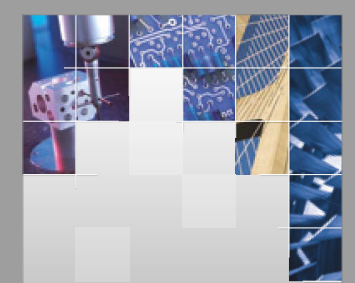

\section{Enfincering}
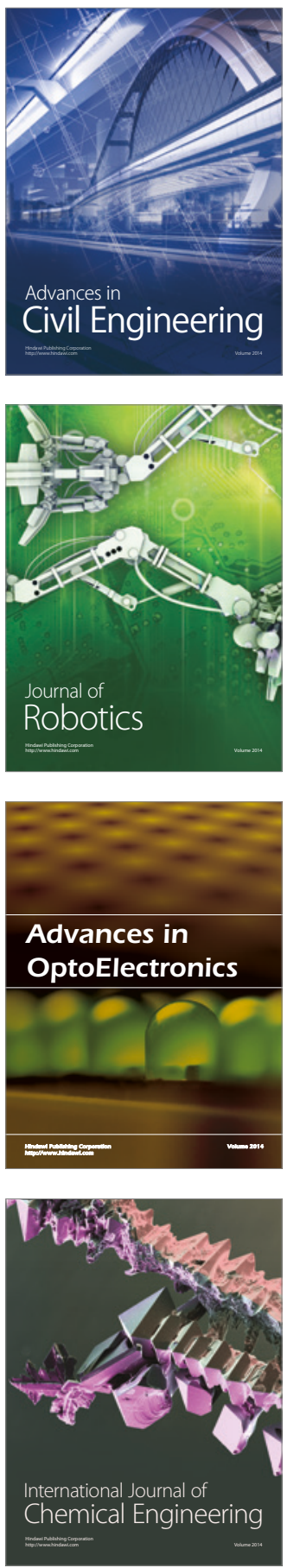

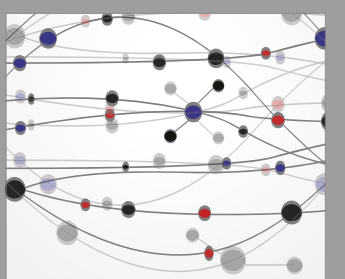

The Scientific World Journal

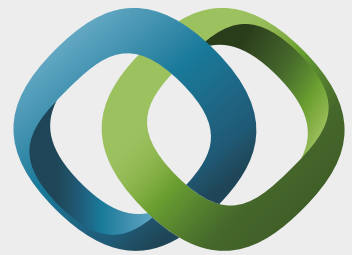

\section{Hindawi}

Submit your manuscripts at

https://www.hindawi.com
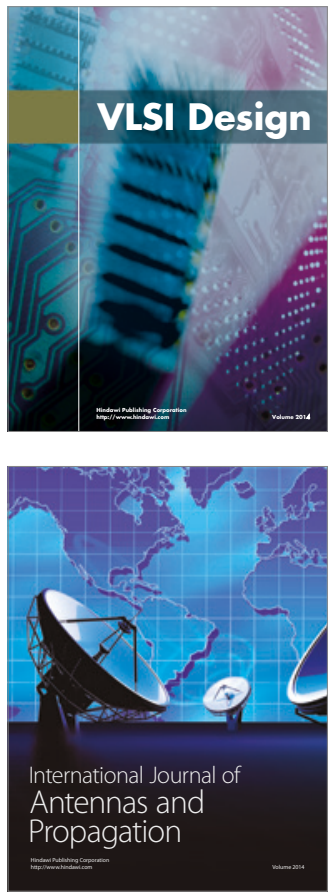

\section{Rotating}

Machinery
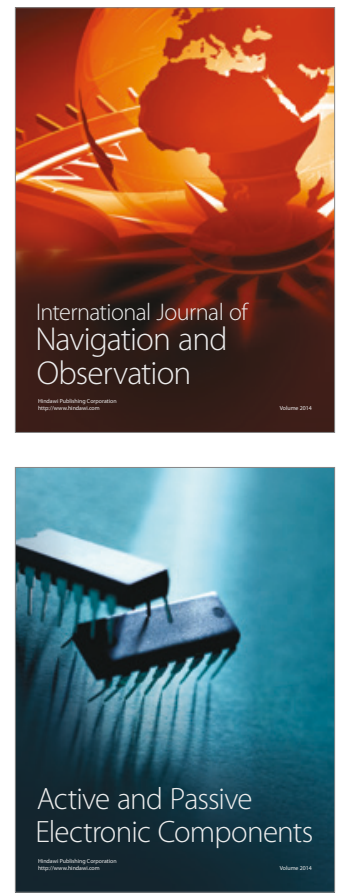
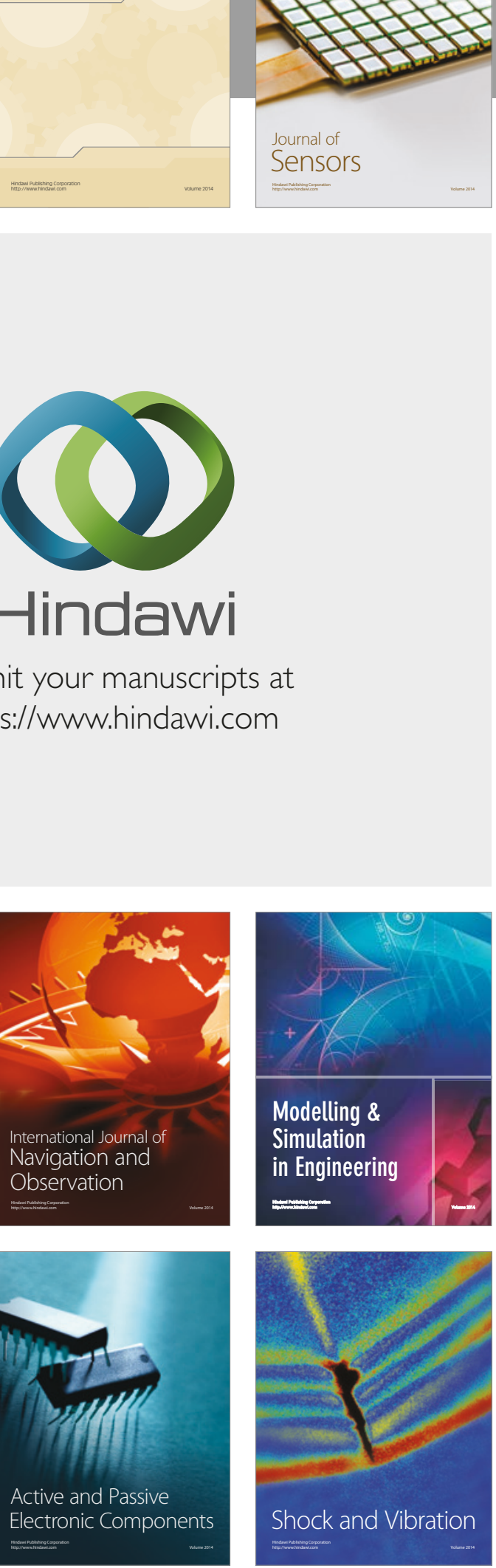
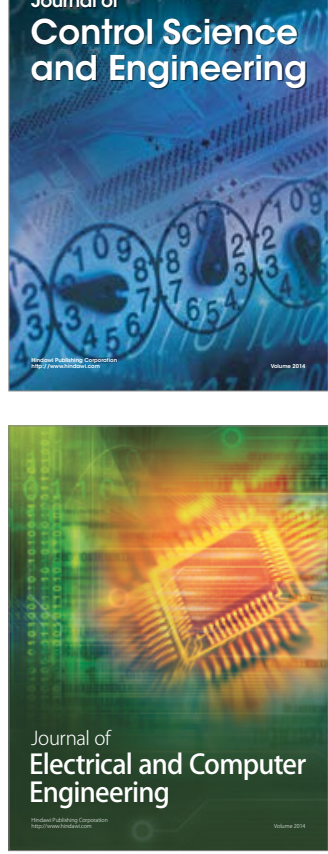

Distributed

Journal of

Control Science

and Engineering
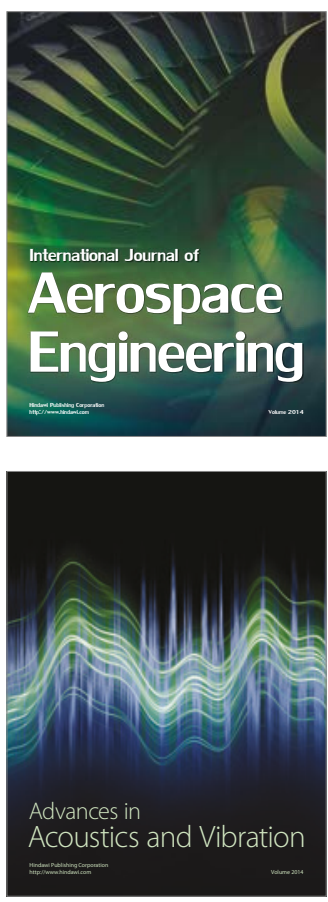

Sensor Networks 